\title{
Protein kinase C-delta (PKC $\delta)$, a marker of inflammation and tuberculosis disease progression in humans, is important for optimal macrophage killing effector functions and survival in mice
}

This article has been corrected since Advance Online Publication and an erratum is also printed in this issue

SP Parihar ${ }^{1,2}$, M Ozturk ${ }^{1,2}$, MJ Marakalala ${ }^{1}$, DT Loots ${ }^{3}$, R Hurdayal $^{1,2,4}$, D Beukes ${ }^{3}$, M Van Reenen ${ }^{3}$, DE Zak ${ }^{5}$, SK Mbandi ${ }^{6}$, F Darboe ${ }^{6}$, A Penn-Nicholson ${ }^{6}$, WA Hanekom ${ }^{6}$, M Leitges ${ }^{7}$, TJ Scriba ${ }^{6}$, R Guler ${ }^{1,2}$ and F Brombacher ${ }^{1,2}$

We previously demonstrated that protein kinase C- $\delta(\mathrm{PKC} \delta)$ is critical for immunity against Listeria monocytogenes, Leishmania major, and Candida albicans infection in mice. However, the functional relevance of PKC $\delta$ during Mycobacterium tuberculosis (Mtb) infection is unknown. PKC $\delta$ was significantly upregulated in whole blood of patients with active tuberculosis (TB) disease. Lung proteomics further revealed that PKC $\delta$ was highly abundant in the necrotic and cavitory regions of TB granulomas in multidrug-resistant human participants. In murine $M$ tb infection studies, $\mathrm{PKC} \delta^{-\prime-}$ mice were highly susceptible to tuberculosis with increased mortality, weight loss, exacerbated lung pathology, uncontrolled proinflammatory cytokine responses, and increased mycobacterial burdens. Moreover, these mice displayed a significant reduction in alveolar macrophages, dendritic cells, and decreased accumulation of lipid bodies (lungs and macrophages) and serum fatty acids. Furthermore, a peptide inhibitor of PKC $\delta$ in wild-type mice mirrored lung inflammation identical to infected $\mathrm{PKC} \delta^{-\prime-}$ mice. Mechanistically, increased bacterial growth in macrophages from $\mathrm{PKC}^{-1-}$ mice was associated with a decline in killing effector functions independent of phagosome maturation and autophagy. Taken together, these data suggest that PKC $\delta$ is a marker of inflammation during active TB disease in humans and required for optimal macrophage killing effector functions and host protection during Mtb infection in mice.

\section{INTRODUCTION}

Protein kinase $\mathrm{C}-\delta(\mathrm{PKC} \delta)$ plays a multitude of physiological roles through its ability to phosphorylate multiple target proteins involved in various cellular processes such as signal transduction, ${ }^{1}$ apoptosis, ${ }^{2}$ proliferation and survival, ${ }^{3}$ transcription, ${ }^{4}$ hormonal regulation, ${ }^{5}$ and immune responses. ${ }^{6,7}$ $\mathrm{PKC} \delta^{-1-}$ mice were originally characterized by two independent research groups who highlighted the role of this kinase in B-cell anergy ${ }^{8}$ and B cell-mediated autoimmunity. ${ }^{9}$ Furthermore, $\mathrm{PKC} \delta^{-1-}$ mice were protected against glucose intolerance induced by high-fat diet by exhibiting reduced accumulation of liver triacylglycerol and impaired production of lipogenic enzymes. ${ }^{10}$ This feature of accumulating fewer lipids during an inflammatory condition by $\mathrm{PKC} \delta^{-/}$mice upon Mycobacterium tuberculosis $(M t b)$ infection might impair its ability to undergo slow-replicating, persistence phase as

${ }^{1}$ Institute of Infectious Diseases and Molecular Medicine (IDM), Division of Immunology and South African Medical Research Council (SAMRC) Immunology of Infectious Diseases, Faculty of Health Sciences, University of Cape Town, Cape Town, South Africa. ${ }^{2}$ International Centre for Genetic Engineering and Biotechnology (ICGEB), Cape Town-Component, Cape Town, South Africa. ${ }^{3}$ Human Metabolomics, North-West University, Potchefstroom, South Africa. ${ }^{4}$ Department of Molecular and Cell Biology, Faculty of Science, University of Cape Town, Cape Town, South Africa. ${ }^{5}$ Center for Infectious Disease Research, Seattle, WA, USA. ${ }^{6}$ South African Tuberculosis Vaccine Initiative (SATVI), Institute of Infectious Disease and Molecular Medicine (IDM) \& Division of Immunology, Department of Pathology, University of Cape Town, Cape Town, South Africa and ${ }^{7} \mathrm{PKC}$ Research Consult, Cologne, Germany. Correspondence: F Brombacher (brombacherfrank@gmail.com) 
reported in human sputum. ${ }^{11}$ Lipids are a prerequisite for the persistence of $M t b$ in macrophages that transforms them into foamy macrophages that contribute to tissue pathology and facilitate dissemination. ${ }^{12}$

Most studies on the role of PKC $\delta$ were performed using inhibitors in vitro that lacked in specificity to a particular PKC isoform. A frequently used chemical rottlerin, which is a nonspecific chemical inhibitor of PKC $\delta$ to block enzymatic reactions and intracellular signaling in pancreatic acinar cells. ${ }^{13}$ Rottlerin was shown to reduce viral burdens in human monocyte-derived macrophages during the early stages of HIV-1 infection. ${ }^{14}$ Physiologically, silencing of PKC $\delta$ with anti-PKC $\delta$ small interfering RNA resulted in increased cholesterol efflux in hamster kidney cells and a murine macrophage cell line RAW264.7. ${ }^{15}$ Moreover, PKC isoforms such as $\delta$ and $\varepsilon$ are required for phagocytosis in RAW264.7 macrophages, ${ }^{16}$ and PKCE also regulates autocrine production of tumor necrosis factor (TNF) that in turn induces apoptosis in lipopolysaccharide-activated macrophages. $^{17}$
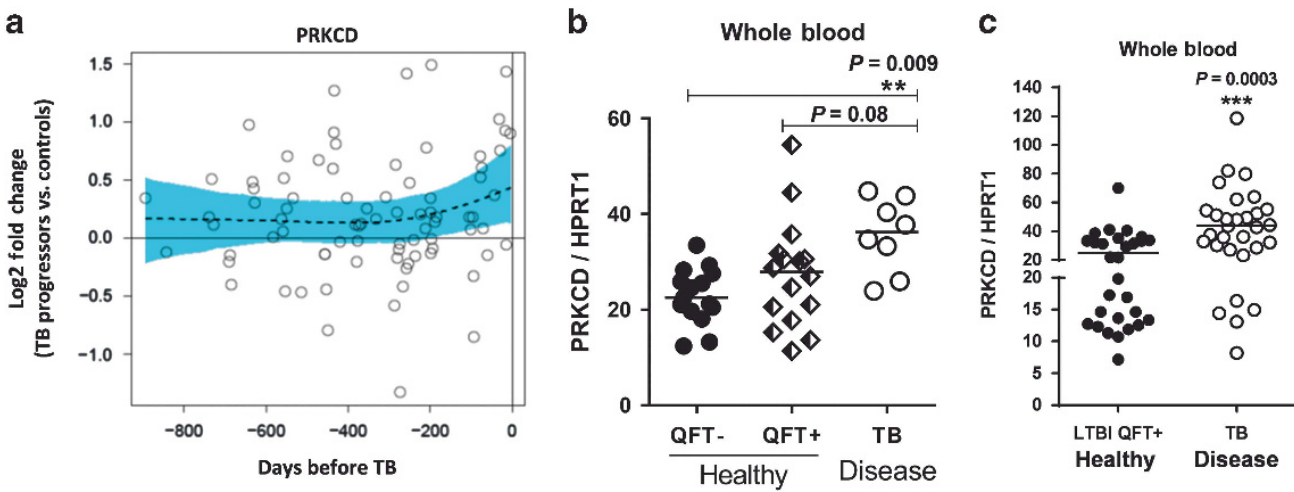

d

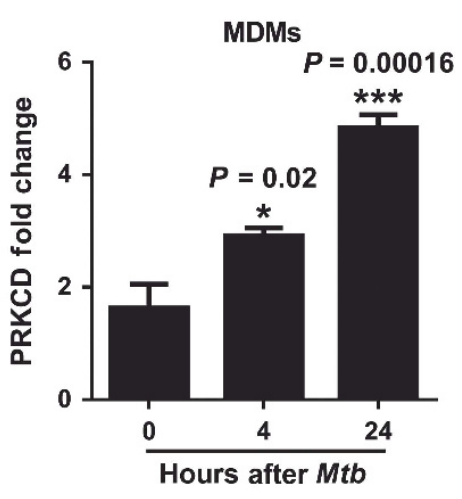

f

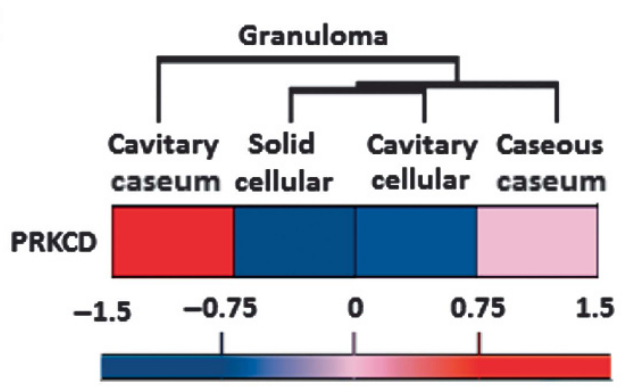

e

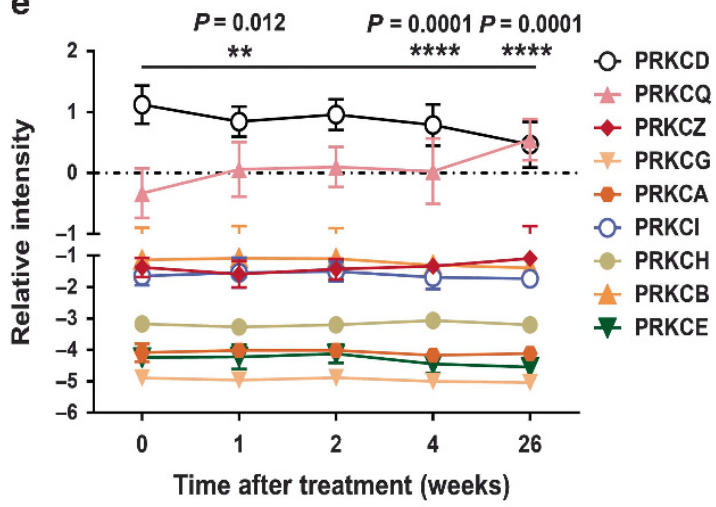

Relative protein abundance z-score

Figure 1 Increased expression of protein kinase-C $\delta(\mathrm{PKC} \delta$ ) in human whole blood, lungs of tuberculosis (TB) patients, and Mycobacterium tuberculosis (Mtb)-infected macrophages. (a) PKC $\delta$ mRNA expression in TB progressors, expressed as log2 fold change over matched controls, from Adolescent Cohort Study (ACS) group. The dotted line represents the mean log2 fold change, nonlinear spline function in 46 progressors and 107 healthy QuantiFERON (QFT)-positive controls. The blue shaded area represents $99 \%$ confidence intervals. (b) mRNA expression of PKC $\delta$ measured in an independent QFT-negative or -positive controls, or patients with active TB disease, from ACS group in a $(n=8-16)$. (c) PKC $\delta$ mRNA expression validated by quantitative reverse transcription-PCR (qRT-PCR) in whole blood from SHIP cohort in adults with active TB disease before the initiation of drug treatment $(n=30)$ or QFT-positive healthy controls ( $n=30$, LTBI, latent Mtb infection). (d) PKC $\delta$ mRNA expression in monocyte-derived macrophages (MDMs) of healthy donors after Mtb infection in vitro $(n=2)$. (e) mRNA expression of PKC isoforms following the onset of antitubercular treatment in human TB patients $(n=27)$. (f) Heat map of $z$-score and log2-transformed label-free quantification of PKC $\delta$ in different types of granulomas, excised from patients infected with multidrug-resistant $M t b(n=5)$. Data are represented as mean \pm s.e.m., analyzed using unpaired Student's $t$-test (c) and one-way analysis of variance (ANOVA) (b-e), ${ }^{\star} P<0.05,{ }^{* \star} P<0.01,{ }^{\star \star \star} P<0.001,{ }^{* \star \star \star} P<0.0001$ vs. control. 
Studies have suggested a functional role for PKC $\delta$ in regulating immunity to infectious diseases in vivo. Previously, using $\mathrm{PKC} \delta^{-1-}$ mice, we demonstrated a crucial role of this kinase in macrophage-mediated phagosomal clearance of the intracellular bacterium, Listeria monocytogenes. ${ }^{7}$ We further reported that $\mathrm{PKC} \delta$ regulates the production of interleukin-12 (IL-12) p40/70 in both macrophages and dendritic cells, required for protective $\mathrm{T}$ helper cell type 1 immune responses in a murine model of cutaneous leishmaniasis. ${ }^{6}$ We also demonstrated that deletion of $\mathrm{PKC} \delta$ renders mice susceptible to Candida albicans infection via Card9-mediated antifungal immunity. ${ }^{18}$ These studies highlighted the key role of PKC $\delta$ in the immune response to infectious diseases. However, the functional significance of $\mathrm{PKC} \delta$ in humans and mice along with its effect on lipid homeostasis in host immunity to tuberculosis (TB) infection has not been studied yet.

Here, we report that PKC $\delta$ mRNA expression is increased in peripheral blood of participants with active TB. In addition, proteomic analysis of lung tissues from treatment-refractory TB patients revealed higher levels of PKC $\delta$ protein expression in caseous and necrotic regions of cavitory granulomas, highlighting that PKC $\delta$ might be an indicator of an inflammation. We further demonstrate that deletion of PKC $\delta$ in mice has a detrimental effect on a host with increased bacterial loads, enhanced lung pathology, and mortality. Moreover, $\mathrm{PKC} \delta$ is critical for the accumulation of lipid bodies in macrophages and lungs during $M t b$ infection. Mechanistically, PKC $\delta$ is important for optimal macrophage killing effector functions, independent of phagosome maturation and autophagy.

\section{RESULTS}

\section{Increased expression of PKC $\delta$ during active TB disease}

Recently, we identified a transcriptomic signature that has the potential to distinguish latent infection from the development of active disease. ${ }^{19}$ Given the pivotal role of PKC $\delta$ in signal transduction, we asked whether expression of this kinase changes during the transition from $M t b$ infection to TB disease. We analyzed gene expression data in whole blood from a nested control study correlating risk of TB from 800 days before diagnosis. This included 46 adolescents with latent $M t b$ infection who progressed to active disease (progressors) and 107 adolescents with $M t b$ infection who remained healthy. ${ }^{19}$ PKC $\delta$ was significantly upregulated in progressors when compared with latently infected healthy controls (Figure 1a). Although two PKC isoforms ( $\theta$ and $\eta$ ) exhibited downregulation during progression to active TB disease, the expression levels of other PKC isoforms $(\alpha, \beta, \gamma, 1, \varepsilon$, and $\zeta$ ) remained constant (Supplementary Figure S1 online). This highlighted PKC $\delta$ as a possible marker of active TB disease that we sought to validate using quantitative real timePCR (qRT-PCR). PKC $\delta$ mRNA expression was significantly higher in whole blood from 8 participants with pulmonary $\mathrm{TB}$ disease when compared with $16 \mathrm{QFT}^{-}$healthy controls $\left(\mathrm{QFT}^{-}\right)$but not with latent $M t b$ infection $\left(\mathrm{QFT}^{+}\right)($Figure 1b).
However, the latter was also significantly higher in whole blood of a larger independent Strategic Health Innovation Partnerships (SHIP) cohort of 30 active TB participants and 30 healthy individuals $\left(\mathrm{QFT}^{+}\right)$with latent $M t b$ infection (Figure 1c). In addition, human monocyte-derived macrophages (MDMs) also upregulated PKC $\delta$ expression following $M t b$ infection (Figure 1d). Collectively, these data indicate that $\mathrm{PKC} \delta$ expression increases during active TB disease and in vitro $M t b$ infection of macrophages.

We then explored whether anti-TB therapy would decrease PKC $\delta$ expression. We analyzed a publicly available data set from an independent study ${ }^{20}$ that reported whole-blood expression profiles of 27 first-time TB patients before and after treatment. We found that PKC $\delta$ was the most abundantly expressed isoform compared with other PKC isoforms. Importantly, the expression decreased from week 1 to 26 weeks of successful treatment with TB therapy (Figure 1e). Of note, all other PKC isoforms remained unchanged before and after TB therapy except PKC $\theta$ that was marginally increased only at completion of treatment (Figure 1e). This decline in PKC $\delta$ expression after treatment suggests that it might be an important component or mediator of the host immune response during active $\mathrm{TB}$ disease.

PKC $\delta$ is highly expressed in necrotic and cavitary regions of granulomas in patients with multidrug-resistant TB

We recently characterized proteomic signatures in various regions of granulomas from treatment-refractory $\mathrm{TB}$ patients who had undergone pneumonectomy due to severe lung damage. ${ }^{21}$ Using the proteomics data, we determined the protein expression levels of various PKC isoforms. Our analysis revealed that only $\mathrm{PKC} \delta$ was associated with the necrotic regions of both caseous and cavitary granulomas (Figure 1f), whereas other PKC isoforms were largely absent in the lung tissue samples (data not shown). This suggests an association of PKC $\delta$ within the regions of $M t b$-specific host immune responses at the site of disease. The abundance of PKC $\delta$ protein at the sites of exaggerated disease strengthens our transcriptomic findings in whole blood, highlighting PKC $\delta$ as a host factor that is induced during the progression of cellular to necrotic granulomas in humans.

\section{PKC $\delta$ is critical for host survival against Mtb infection in mice}

To further investigate how $\mathrm{PKC} \delta$ influences host mortality during $M t b$-infection, we compared $\mathrm{PKC} \delta^{-1-}$ mice ${ }^{6,7}$ with wild-type controls in a murine model of experimental TB. Deletion of PKC $\delta$ rendered mice highly susceptible to various doses of intranasal $M t b$ infection (Figure 2a,d,g). Earlier and increased mortality was associated with rapid weight loss (Figure 2b,e,h) and increased bacterial titers in the lungs and spleen determined at the time of killing (Figure $\mathbf{2 c}, \mathbf{f}, \mathbf{i}$ ). Thus, $\mathrm{PKC} \delta$ deficiency in mice results in increased bacterial burdens and mortality during $M t b$ infection. 

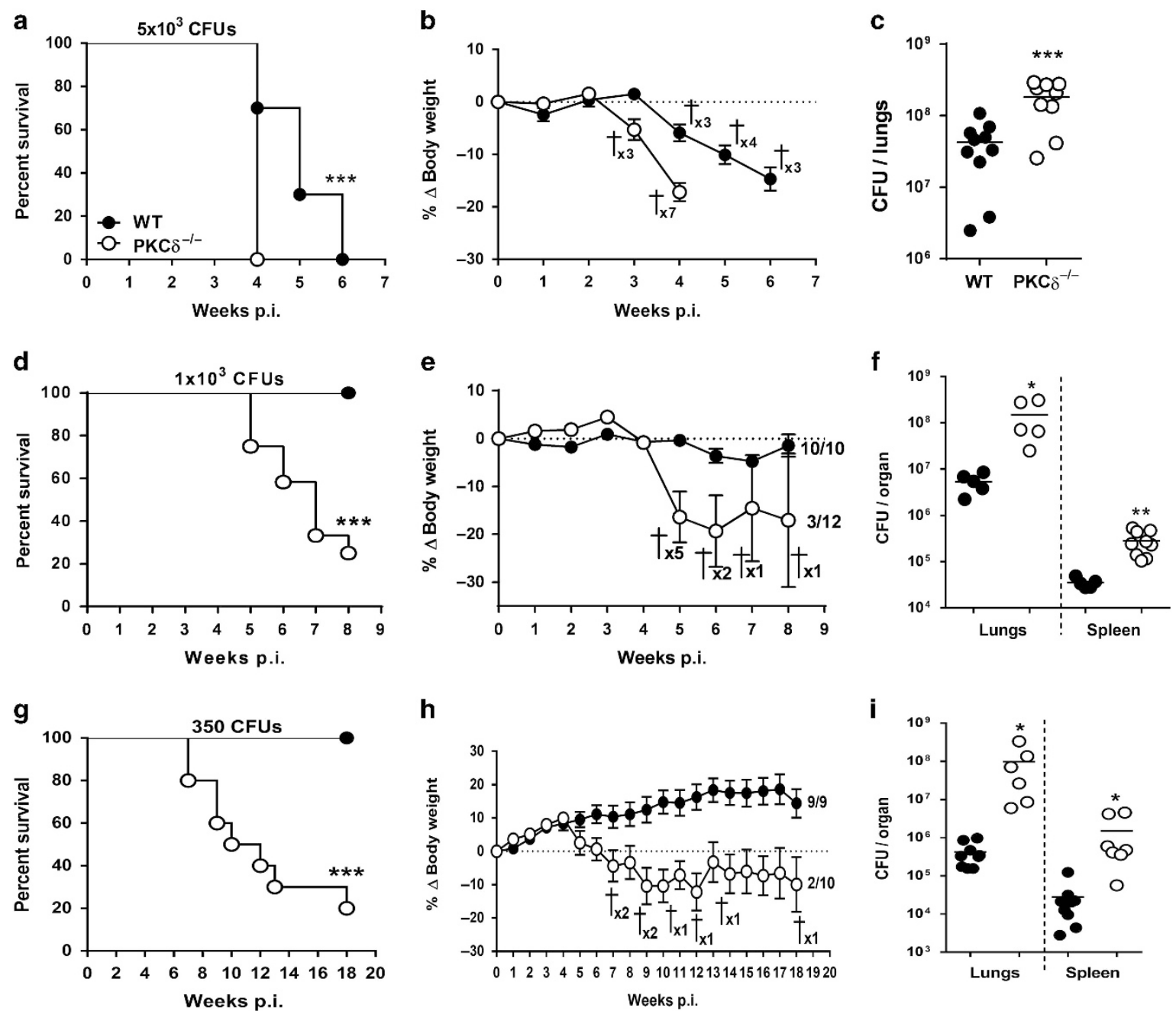

Figure 2 Protein kinase-C $\delta$-deficient $\left(\mathrm{PKC} \delta^{-1-}\right)$ mice displayed enhanced mortality and mycobacterial burdens. Mice were infected with a range of Mycobacterium tuberculosis $(\mathrm{Mtb})(\mathrm{H} 37 \mathrm{Rv})$ doses via intranasal challenge for mortality studies. Survival curve, body weight change, and lung bacterial burden determined at the time of killing. (a-c) A total of 5,000 colony-forming units (CFUs) after 6 weeks; (d-f) 1,000 CFUs after 8 weeks; and (g-i) 350 CFUs after 18 weeks. Mortality curves were analyzed by Kaplan-Meyer survival test, ${ }^{* *} P<0.01,{ }^{* \star *} P<0.001$ vs. wild-type (WT) control mice. Data are represented as mean \pm s.e.m. of $9-10$ mice/group, analyzed using unpaired Student's $t$-test, ${ }^{\star} P<0.05,{ }^{\star \star} P<0.01,{ }^{* \star \star} P<0.001$ vs. control.

\section{Exacerbated histopathology and reduced accumulation of lipid bodies in the lungs of $\mathrm{PKC} \delta^{-1-}$ mice during Mtb infection}

As PKC $\delta$ mice succumbed to $M t b$ infection as early as 4 weeks in mortality studies (Figure 2d), we performed an in-depth analysis of disease parameters at 4 and 8 weeks using a dose of 1,000 colony-forming units (CFU). At 4 and 8 weeks after infection, $\mathrm{PKC} \delta^{-1-}$ mice displayed higher lung and spleen burdens (Figure 3a), corroborating the mortality findings. Susceptibility to infection in $\mathrm{PKC} \delta^{-1-}$ mice was further accompanied by a significant increase in lung inflammation as revealed by lung weight index (Figure $\mathbf{3 b}$ ), higher pulmonary cell recruitment (Figure 3c), and larger lesion area in hematoxylin and eosin-stained lung sections at 4 and 8 weeks after infection (Figure 3d). Furthermore, immunohistochemistry revealed that inducible nitric oxide synthase (iNOS) production was significantly increased in the lungs of $\mathrm{PKC}^{-1-}$ mice, concomitant with increased pulmonary tissue pathology indicating that $\mathrm{PKC} \delta$ might directly or indirectly contribute to the control of lung pathology (Figure 3e). Given the importance of PKC $\delta$ in the accumulation of cholesterol in human monocyte-derived macrophages, ${ }^{22}$ we investigated lipid accumulation in the lungs of $\mathrm{PKC} \delta^{-1-}$ mice. Oil Red O staining of lung tissue sections of $\mathrm{PKC} \delta^{-1-}$ mice displayed significantly reduced accumulation of lipids in lungs when compared with wild-type animals after 4 and 8 weeks of infection (Figure 3f). We next assessed whether inhibiting PKC $\delta$ in wild-type mice using a specific peptide inhibitor TatV $\delta 1.1$ (ref. 23) would recapitulate exaggerated lung pathology of $\mathrm{PKC} \delta^{-1-}$ mice following $M t b$ infection. Indeed, mice treated with $\mathrm{Tat} V \delta 1.1$ had significantly higher lung weight index and more inflamed lung sections and lesion size when compared with wild-type animals (Supplementary Figure S2a-c). Together, these results demonstrate that absence of PKC $\delta$ in $M t b$ infection resulted in exacerbated pathology and reduced accumulation of lipids in the lungs. 

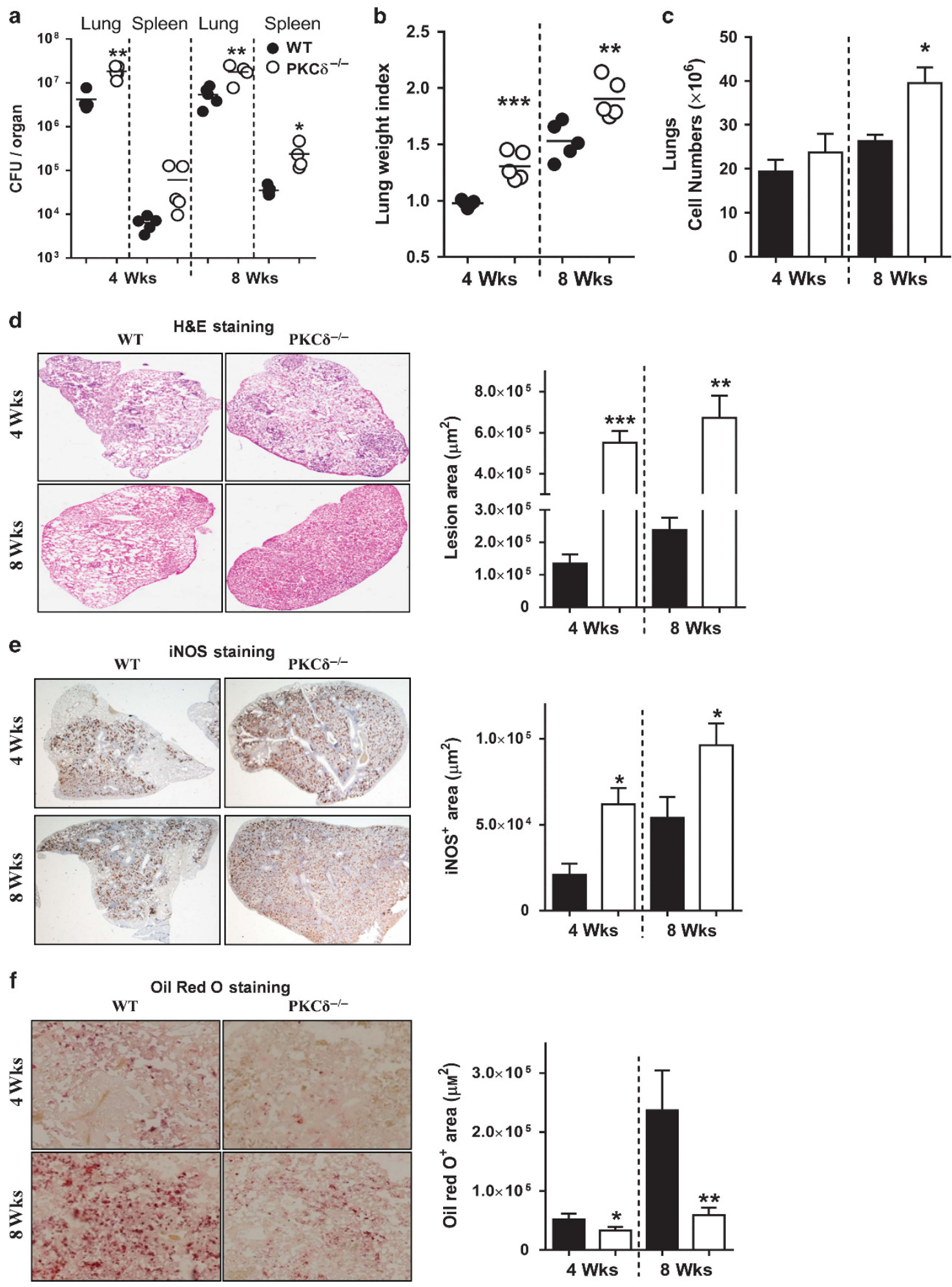

Figure 3 Protein kinase-C $\delta$-deficient $\left(\mathrm{PKC} \delta^{-l-}\right.$ ) mice displayed increased lung pathology and nitric oxide and decreased lipid accumulation in the lungs. Mice were infected with Mycobacterium tuberculosis (Mtb) (1,000 colony-forming units (CFUs)) via intranasal challenge. (a) Bacterial burden in lungs and spleens, (b, c) lung weight index, as a proxy for inflammation, and (c) total number of cells harvested. (d-f) Representative images and quantification of histopathology, (d) hematoxylin and eosin (H\&E) staining and lesions, (e) immunohistochemistry for inducible nitric oxide synthase (iNOS), and (f) Oil Red O staining for lipids in the lungs at 4 and 8 weeks after infection. Data are represented as mean \pm s.e.m. of $n=4-5$ mice/group and are representative of two independent experiments. Data are analyzed using unpaired, Student's $t$-test, ${ }^{\star} P<0.05,{ }^{* \star} P<0.01,{ }^{* * *} P<0.001$, vs. wild-type (WT) control. 
Increased proinflammatory cytokine responses in the lungs of $\mathrm{PKC} \delta^{-l-}$ mice following Mtb infection

Following excessive lung pathology and increased bacterial loads in PKC $\delta^{-1-}$ mice (Figure 3d), we measured the proinflammatory cytokines in the lungs of mice. Compared with wild-type mice, $\mathrm{PKC} \delta^{-1-}$ mice showed marked increases in proinflammatory cytokines including interferon (IFN)- $\gamma$, TNF, IL-1 $\beta$, IFN- $\beta$, and IL- 6 with minor effect on IL-10 at week 4 (Figure 4a) and week 8 (Figure $4 \mathbf{b}$ ) after infection. In the lungs of wild-type mice, the extent of proinflammatory cytokines response is $M t b$ infection dose dependent (Supplementary Figure S5f). Furthermore, flow cytometric analysis of various pulmonary immune cell populations in $\mathrm{PKC} \delta^{-/-}$ mice after 4 and 8 weeks of infection demonstrated that frequencies and total cell numbers of alveolar macrophages (Figure $\mathbf{4 c , f , i , 1 )}$ and dendritic cells (Figure $\mathbf{4 d , g , j , m}$ ) were significantly decreased with concomitant increase in activated macrophages (Figure 4g) when compared with wild-type mice. Of note, we observed no major differences in the frequencies and cell numbers of lymphocytes (CD4 ${ }^{+}, \mathrm{CD} 8{ }^{+} \mathrm{T}$ and $\mathrm{B}$ cells) (Figure 4e,h,k,n) or neutrophils (Figure $4 \mathbf{c}, \mathbf{f}, \mathbf{i}, \mathbf{l}$ ) infiltrating the lung. Gating strategy defining myeloid cell populations in the lungs are shown (Supplementary Figure S2d). In addition, we showed that percentages of $\mathrm{T}$ cells were decreased and that of dendritic cells were increased in thoracic lymph nodes at week 4 (Supplementary Figure S3a-d) but not at week 8 after infection (Supplementary Figure S3e-h). Together, these results indicated that the absence of PKC $\delta$ increased inflammatory cytokine responses and decreased alveolar macrophages and dendritic cells in lungs of $M t b$-infected mice.

\section{Decreased fatty acids in serum of $\mathrm{PKC} \delta^{-l-}$ mice following Mtb infection}

Decreased lipid accumulation in lungs of $\mathrm{PKC} \delta^{-/-}$mice during $M t b$ infection prompted us to perform a total metabolome extraction of the serum in these animals. Principal component analysis showed a clear differentiation between $M t b$-infected (1,000 CFUs) wild-type and $\mathrm{PKC} \delta^{-1-}$ mice at week 4 (62\% variance) and week 8 (64\% variance) after infection, respectively (Figure 5a,b). Metabolite profiles of these two groups thus varied significantly to allow a natural grouping of the individual samples. Fatty acids are determined to be of significance via univariate and multivariate statistical analysis presented in Tables $\mathbf{1}$ and $\mathbf{2}$. Considering these results, $M t b$-infected $\mathrm{PKC} \delta^{-1-}$ mice showed significantly decreased levels of all serum fatty acids when compared with wild-type mice, except for mead acid, an elevation of which is a wellknown marker for fatty acid deficiencies. ${ }^{24}$ Here, we selectively report that host-protective (arachidonic acid, $\alpha$-linoleic acid, and palmitic acid) ${ }^{25}$ and host-detrimental (behenic acid, cervonic acid/docosahexaenoic acid, and timnodonic acid/ eicosapentaenoic acid) ${ }^{25}$ fatty acids were significantly lower in the PKC $\delta^{-1-}$ mice during $M t b$ infection (Figure $\mathbf{5 c}, \mathbf{d}$ ). To assess whether the observed effect was indeed PKC $\delta$ specific and not a consequence of morbidity and pathology at this dose resulted in reduced food/water intake, we performed metabolomics at a low dose (70 CFUs) and found similar results (Supplementary Figure S5a-d) as with 1,000 CFUs (Figure 5). Notably, we confirmed that the changes in lipid profiles were not a function of bacterial loads in the lungs of wild-type mice (Supplementary Figure S5e). Thus, the absence of PKC $\delta$ led to a marginal decrease in serum fatty acids of $M t b$-infected mice.

\section{Macrophages deficient in PKC $\delta$ exhibit reduced mycobacterial killing capacity and reduced accumulation of lipid bodies}

Using our publically available data set from CAGE sequencing of macrophages infected with a hypervirulent $M t b$ strain (HN878), ${ }^{26}$ we reported that PKC $\delta$ in the murine bone marrow-derived macrophages (BMDMs) was also upregulated, whereas other PKC isoforms (except $\beta$ ) remained largely unaffected (Figure 6a), PKC $\delta$ expression was also validated by qRT-PCR in murine macrophages (Supplementary Figure S4a). Given the entire study was performed with an $\mathrm{H} 37 \mathrm{Rv}$ strain of $M t b$, we measured the expression of PKC $\delta$ in H37Rv-infected macrophages (Figure 6b) that had slightly different kinetics at $24 \mathrm{~h}$ after infection when compared with HN878-infected macrophages (Figure 6a and Supplementary Figure S4a). This discrepancy in expression kinetics at $24 \mathrm{~h}$ was most likely due to the different strains of $M t b$. We next investigated the intracellular growth of $M t b$ in $\mathrm{PKC} \delta^{-/-}$ macrophages. Mycobacterial growth was significantly increased in $\mathrm{PKC} \delta^{-1-}$ macrophages particularly at 3 and 6 days after infection (Figure 6c) as well as in wild-type macrophages transfected with anti-PKC $\delta$ small interfering RNA at $48 \mathrm{~h}$ after infection (Supplementary Figure S4b). In $\mathrm{PKC} \delta^{-1-}$ mice, we found a reduced accumulation of the lipid bodies in the $M t b$-infected lungs. Similarly, $\mathrm{PKC} \delta^{-1-}$ macrophages displayed fewer lipid bodies revealed by the Oil Red O staining (red) in fluorescent microscopy in a time-dependent manner concomitant with significantly higher bacterial numbers (Rv-GFP, green) (Figure 6d,e). Unlike in the in vivo model, we found no differences in cytokine production by $\mathrm{PKC} \delta^{-1-}$ BMDMs except for a significant decrease in IL-6 (Figure 6f-i), suggesting other cell populations contributed in the lungs. Thus, PKC $\delta$ is important for macrophage-mediated containment of mycobacteria and lipid accumulation.

\section{Killing effector functions in Mtb-infected PKC $\delta^{-I-}$ macrophages}

The PKC isoforms, including $\beta^{27}$ and $\alpha,{ }^{28}$ were reported to be important for maturation of $M t b$-containing phagosomes. In bacterial infection, we previously reported that $\mathrm{PKC} \delta$ is critical for containment of L. monocytogenes in phagosomes of macrophages. ${ }^{7}$ Surprisingly in $M t b$ infection, no differences in the analyzed phagosome markers including LAMP-1, LAMP-3, Cathepsin-D, and an autophagy marker LC3-II were observed between $\mathrm{PKC} \delta^{-1-}$ and control macrophages (Figure 7a,b). This result suggests that PKC $\delta$ is dispensable for phagosome and autophagy-mediated killing of $M t b$ in macrophages. 

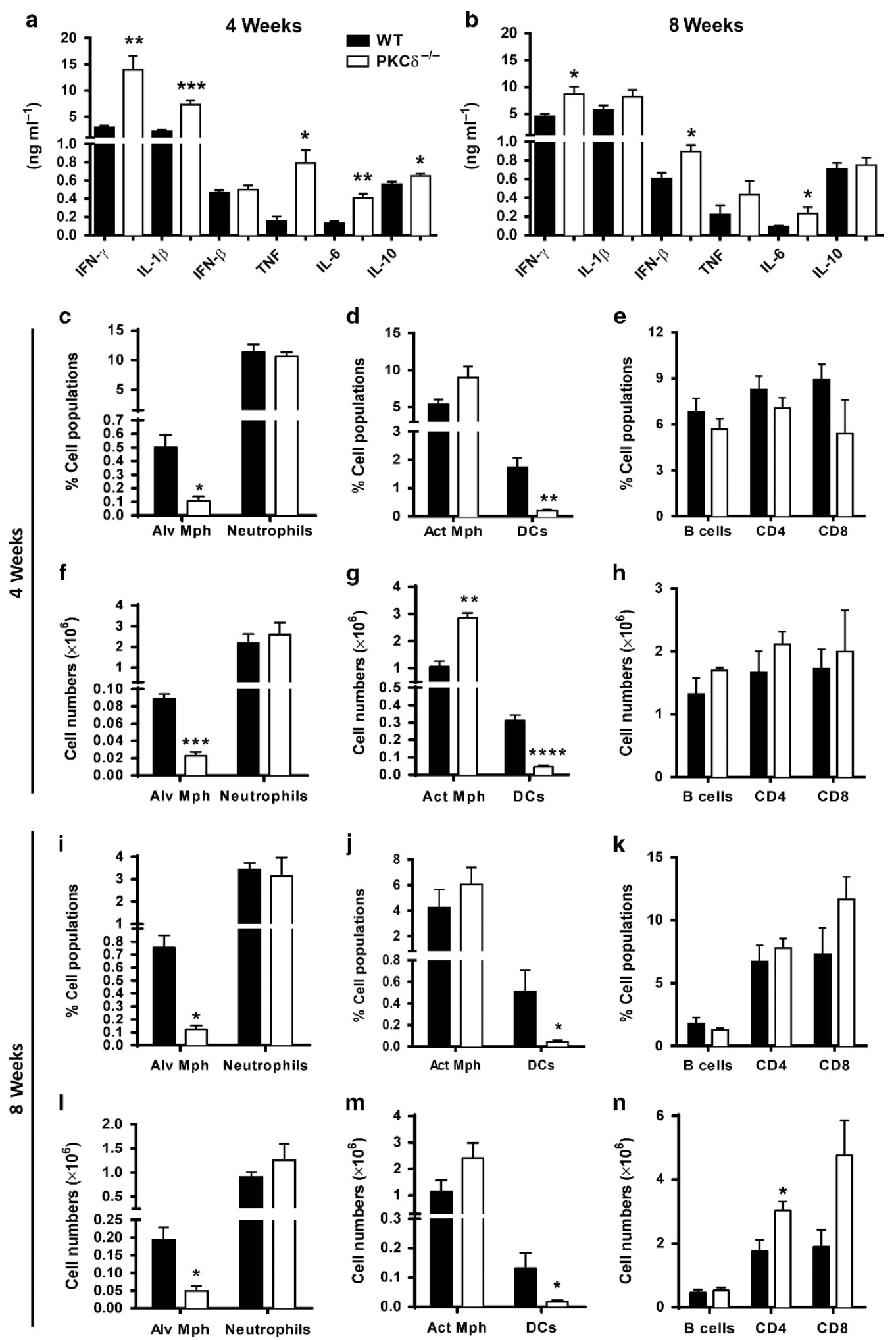

Figure 4 Increased proinflammatory cytokine responses and the immune cell populations in the lungs of protein kinase-C $\delta$-deficient $\left(P K C \delta^{-/-}\right)$mice following Mycobacterium tuberculosis (Mtb) infection. (a, b) Supernatants from lung homogenates were analyzed for interferon- $\gamma$ (IFN- $\gamma$ ), tumor necrosis factor (TNF), interleukin (IL)-1 $\beta$, IL-10, and IFN- $\beta$ using enzyme-linked immunosorbent assay (ELISA) after 4 and 8 weeks of $M$ tb infection. Single-cell suspension of lung tissue was analyzed for percentage and total cell numbers of immune cell populations at 4 (c-h) and 8 (i-n) weeks after infection. Surface markers of different cell populations are as follows: $\mathrm{B}$ cells $=\mathrm{CD} 19^{+} \mathrm{CD} 3^{-}, \mathrm{CD} 4^{+} \mathrm{T}_{\text {cells }}=\mathrm{CD} 3^{+} \mathrm{CD} 4^{+}, \mathrm{CD} 8^{+} \mathrm{T}_{\text {cells }}=\mathrm{CD} 3^{+} \mathrm{CD} 8^{+}, \mathrm{Alveolar}$ $\mathrm{Mphs}=$ SiglecF $^{+} \mathrm{CD} 11 \mathrm{c}^{+}$Autoflourescence ${ }^{+}$, Activated Mphs $=\mathrm{CD}_{11 \mathrm{~b}}{ }^{+} \mathrm{MHCII}^{+} \mathrm{CD}_{11 \mathrm{c}}{ }^{-}, \mathrm{DCs}=\mathrm{CD} 11 \mathrm{c}^{+} \mathrm{MHCII}^{+} \mathrm{CD}_{11 \mathrm{~b}}{ }^{+}$, and Neutrophils $=$ $\mathrm{Gr}^{+}{ }^{+} \mathrm{CD} 11 \mathrm{c}^{-}$. Data are represented as mean \pm s.e.m. of $n=4-5$ mice/group and are representative of two independent experiments. Data are analyzed using unpaired Student's $t$-test, ${ }^{*} P<0.05,{ }^{* \star} P<0.01$, ${ }^{* * *} P<0.001,{ }^{* \star * \star} P<0.0001$, vs. wild-type (WT) control mice. Act, activated; Alv, alveolar; Mph, macrophage. 
a
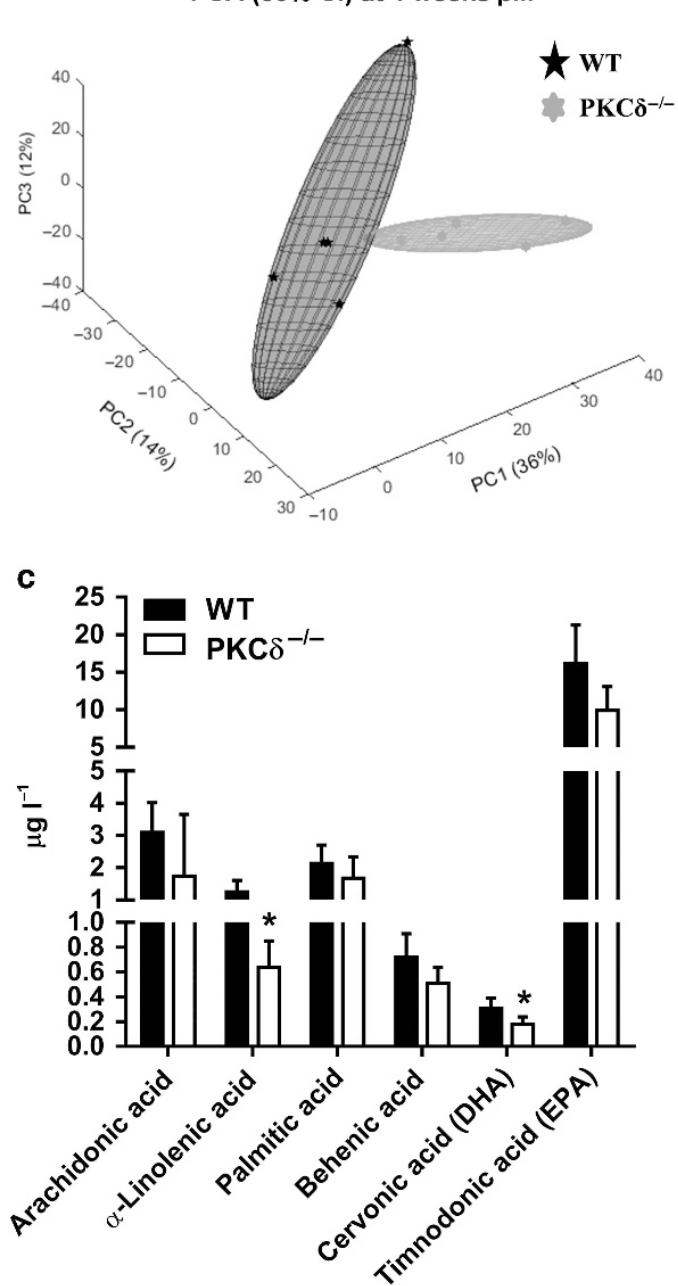

b
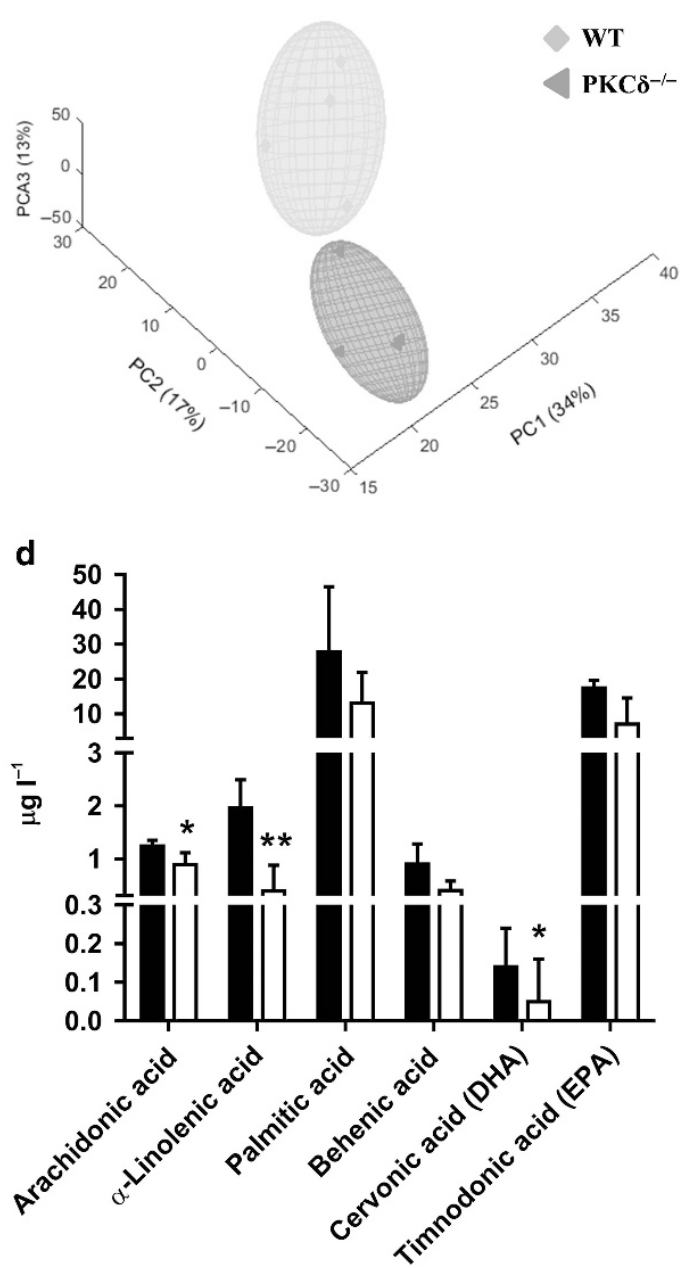

Figure 5 Decreased serum fatty acids by metabolic analysis following Mycobacterium tuberculosis (Mtb) infection. (a, b) Principal component analysis (PCA) plots with percentage variation for each PC are indicated in parenthesis on the respective axis at 4 and 8 weeks after infection (1,000 colonyforming units (CFUs)). (c, d) Serum levels $\left(\mu \mathrm{gl}^{-1}\right.$ ) of selected host-protective (arachidonic acid, $\alpha$-linolenic acid, and palmitic acid) and host-detrimental fatty acids (behenic acid, docosahexaenoic acid (DHA), and eicosapentaenoic acid (EPA)) during Mtb infection at 4 and 8 weeks after infection. Data are represented as mean \pm s.d. of $n=4-5$ mice/group. Data are analyzed using univariate and multivariate statistical techniques (PCA powers $>0.5$, PLSDA VIP $>1.0$, effect size $>0.8$, and Student's $t$-test $p<0.05$ ) vs. wild-type $(W T)$ control mice. Individual fatty acid levels are analyzed by Student's $t$-test ${ }^{\star} P<0.05,{ }^{\star *} P<0.01$.

As the intracellular killing of $M t b$ is enhanced by nitrogen and oxygen species, ${ }^{29}$ we measured the ability of isolated macrophages to release reactive oxygen species (ROS), hydrogen peroxide $\left(\mathrm{H}_{2} \mathrm{O}_{2}\right)$, and nitric oxide (NO). We found $\mathrm{NO}$ production was significantly decreased in $\mathrm{PKC} \delta^{-1-}$ macrophages at the protein level (Figure 7c) and mRNA level using qRT-PCR (Figure 7d). In addition to NO, the release of $\mathrm{H}_{2} \mathrm{O}_{2}$ (Figure 7e) and ROS (Figure 7f) was also significantly decreased in the $\mathrm{PKC} \delta^{-1-}$ macrophages. Furthermore, the absence of PKC $\delta$ in macrophages during $M t b$ infection also renders them more prone to apoptosis, revealed by Annexin V and 7-aminoactinomycin D staining (Figure 7g). Moreover, we also evaluated the possible effect of antimicrobial molecules secreted into the cell supernatant by $M t b$-infected macrophages by incubating infected $\mathrm{PKC} \delta^{-1-}$ cells with supernatants from wild-type cells, and vice versa. Supernatant from infected wild-type macrophages indeed reduced bacterial growth in
$M t b$-infected $\mathrm{PKC} \delta^{-1-}$ macrophages (Figure 7h). This indicates that a deficiency of PKC $\delta$ decreases optimal oxidative and nitrosative killing effector functions in macrophages thereby favor bacterial growth.

\section{PKC $\delta^{-1-}$ macrophages modestly decreased $M t b$ growth in the presence of Ox-LDLs}

Of interest, from decreased lipids in lungs (Figure 3f), macrophages (Figure 6d), and serum fatty acids (Figure $\mathbf{5 c}, \mathbf{d}$ ) of PKC $\delta^{-l-}$ mice, we asked whether foam cell formation using oxidized low-density lipoproteins (Ox-LDLs) would control the growth of $M t b$ in otherwise susceptible $\mathrm{PKC} \delta^{-1-}$ macrophages. Upon pretreatment with Ox-LDLs, we found significantly decreased bacterial growth (Figure 7i) and NO production (Supplementary Figure S4d) in $\mathrm{PKC} \delta^{-1-}$ macrophages when compared with wild-type cells. Furthermore, Ox-LDLs pre-treated $\mathrm{PKC} \delta^{-1-}$ macrophages revealed 
Table 1 Serum fatty acid concentrations $\left(\mu \mathrm{gl}^{-1}\right)$ for wild type and $\mathrm{PKC} \delta^{-I-}$ at 4 weeks after infection

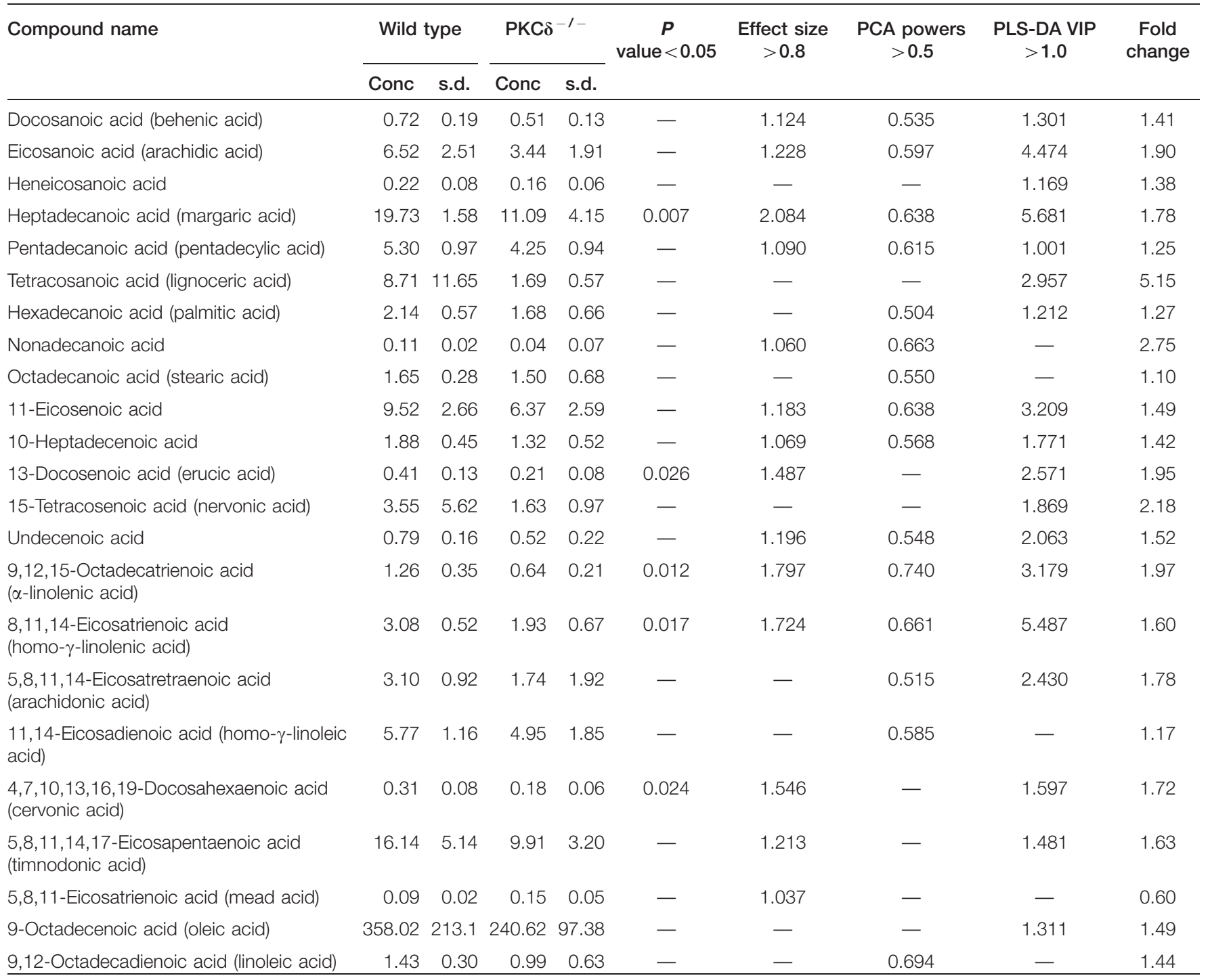

Abbreviations: Conc, concentration; PCA, principal component analysis; PLS-DA VIP, partial least square discriminant analysis variable importance in the projection; $\mathrm{PKC} \delta^{-1-}$, protein kinase- $\mathrm{C} \delta$-deficient.

a modest decrease in growth of $M t b$ when compared with untreated $\mathrm{PKC} \delta^{-1-}$ cells (Figure 7i). On the other hand, wild-type macrophages in the presence of Ox-LDLs showed a significant increase in bacterial growth when compared with untreated wild-type cells (Figure 7i). In addition, Ox-LDLs increased lipid accumulation in wild-type macrophages but not in $\mathrm{PKC} \delta^{-1-}$ macrophages (Supplementary Figure S4e).

Moreover, we evaluated the effect of an unsaturated (oleic acid), saturated (palmitic acid) fatty acids, and native-LDLs on $\mathrm{PKC} \delta^{-1-}$ macrophages. In contrast to Ox-LDLs, we found a significant increase in growth of $M t b$ in $\mathrm{PKC}^{-1-}$ macrophages (Supplementary Figure S4c) with a concomitant decrease in production of NO (Supplementary Figure S4d) in the presence of oleic acid and native-LDLs. Interestingly, macrophages treated with palmitic acid had no effect on $M t b$ growth (Supplementary Figure S4c). Further- more, macrophages treated with oleic acid, palmitic acid, and native-LDLs had no major effect on lipid accumulation (Supplementary Figure S4e). Collectively, these findings suggest that fatty acids have a differential effect on the PKC $\delta$ signaling during mycobacterial growth in vitro and might not be a major contributing factor for increased mycobacterial burdens observed in vivo.

\section{DISCUSSION}

We have demonstrated the functional role of PKC $\delta$ in host defense against $M t b$ infection in humans and mice. PKC $\delta$ is highly expressed in human whole blood during active TB disease progression as well as within the $M t b$-specific proinflammatory regions of necrotic and cavitary lung granulomas during TB disease. These regions of high proinflammatory signatures are required for an early control of bacterial replication and could lead to necrotic damage (caseation) 

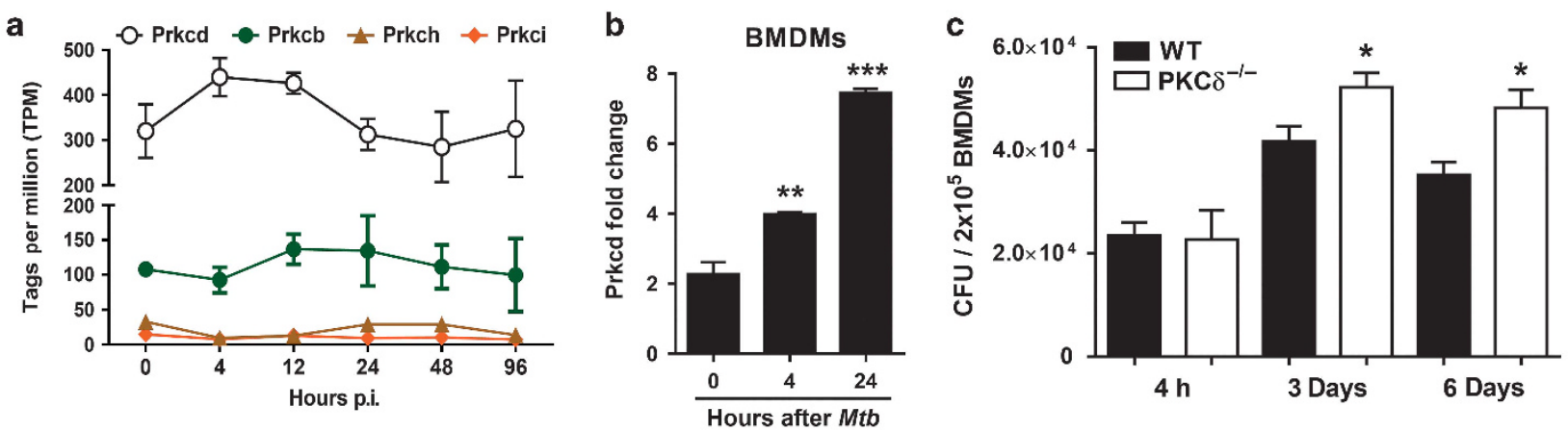
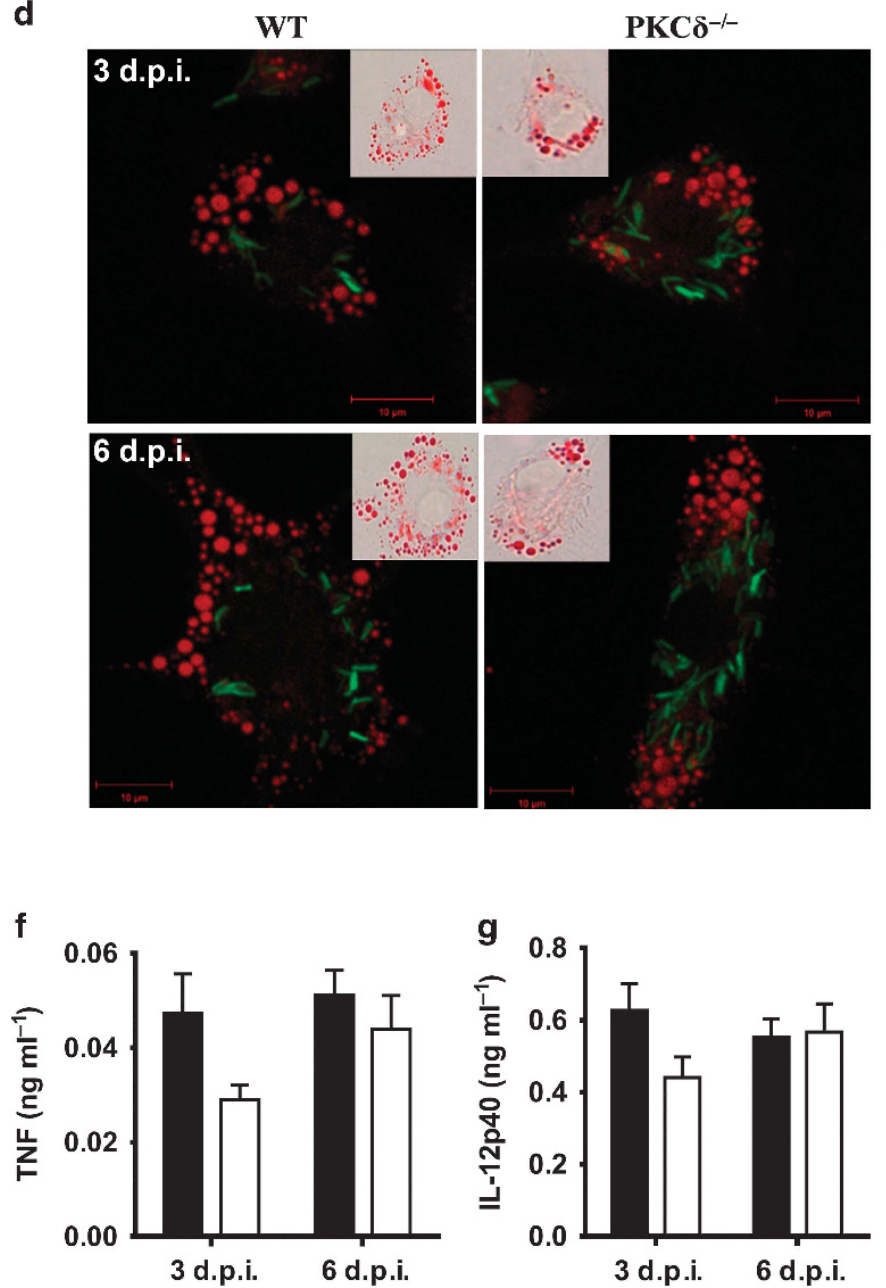
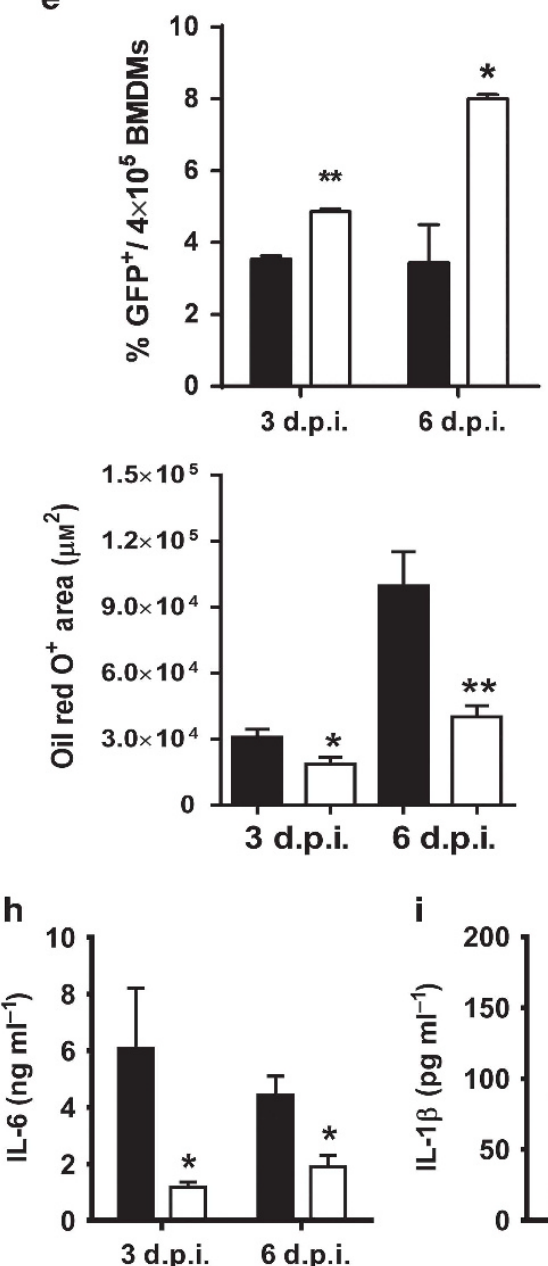

Figure 6 Increased mycobacterial growth and decreased lipid bodies in protein kinase-C $\delta$ (PKC $\delta$ )-deficient macrophages. (a) Expression of PKC $\delta$ and other isoforms in bone marrow-derived macrophages (BMDMs) infected with an HN878 strain of Mycobacterium tuberculosis (Mtb) from CAGE study. (b) PKC $\delta$ mRNA expression during H37Rv Mtb infection in BMDMs using quantitative reverse transcription-PCR (qRT-PCR). (c) Increased growth of H37Rv Mtb (multiplicity of infection $(\mathrm{MOI})=2$ ) in macrophages deficient for PKC $\delta$ during the course of infection. (d, e) PKC $\delta$ - ${ }^{-}$and wild-type (WT) BMDMs were infected with green fluorescent protein (GFP)-expressing Mtb (green, H37Rv) and stained with Oil Red O (red) for visualization and determination of intracellular bacteria and quantification of lipid bodies (inset is bright-field view). (f-i) Cell-free supernatants from infected macrophages were analyzed for the production of tumor necrosis factor (TNF), interleukin (IL)-12p40, IL-6, and IL-1 $\beta$ at indicated time points after infection by enzyme-linked immunosorbent assay (ELISA). Data are represented as mean \pm s.e.m. of quadruplicate and representative of three independent experiments. Data are analyzed using unpaired Student's $t$-test, ${ }^{\star} P<0.05,{ }^{\star \star} P<0.01,{ }^{\star * \star} P<0.001$, vs. WT control macrophages.

and consequent cavity formation if not appropriately regulated. ${ }^{30}$ Evidently, PKC $\delta$ was more abundant in the caseous and cavitary regions in this study, colocalizing with antimicrobial signatures ${ }^{21}$ and the regions of abundant lipids in granulomas. ${ }^{31}$ However, it is not clear whether mediators of inflammation and antimicrobials are responsible for the overwhelming inflammation at the site of infection, or they are remnants of a robust immune response meant to eliminate 


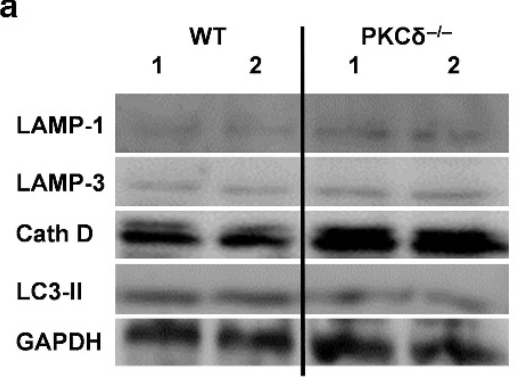

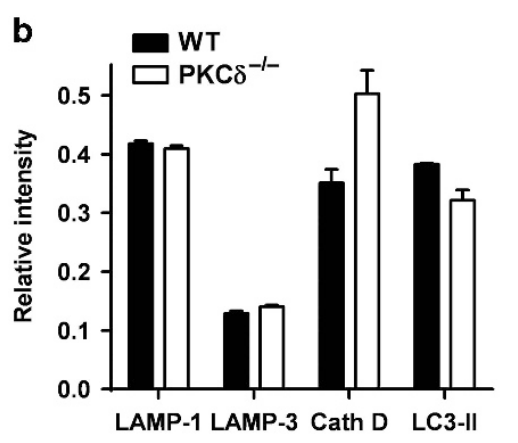

C

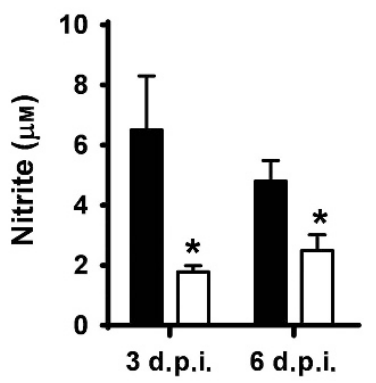

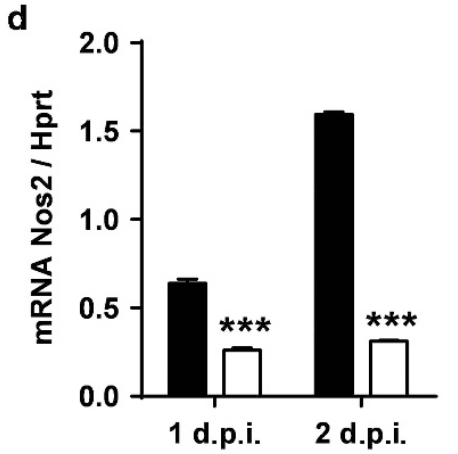

g

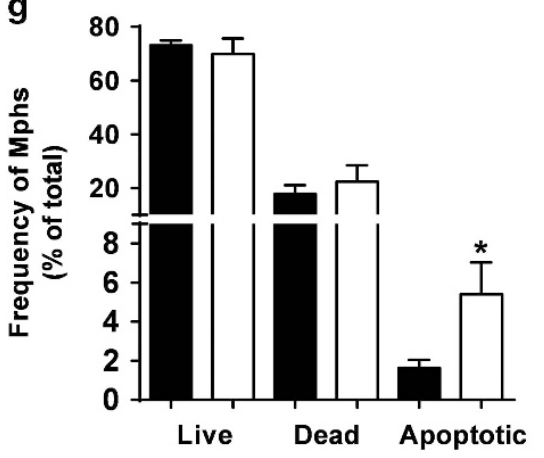

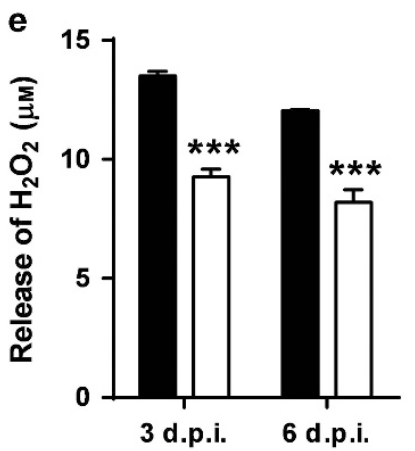

h

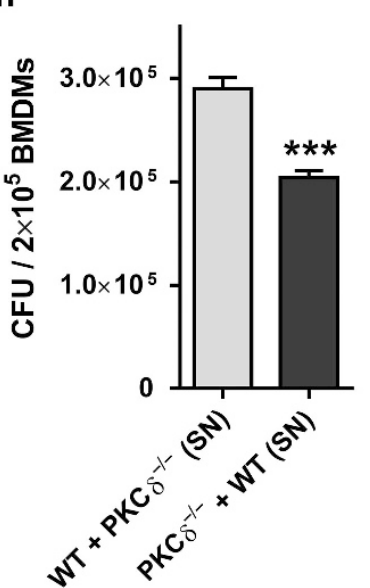

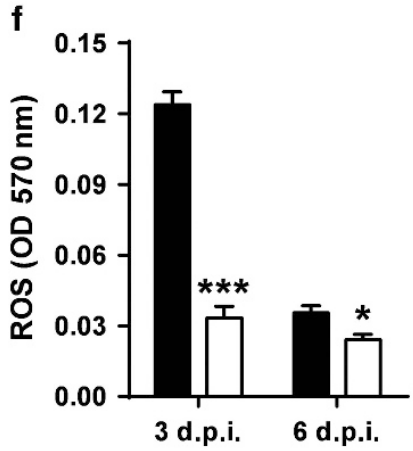

i

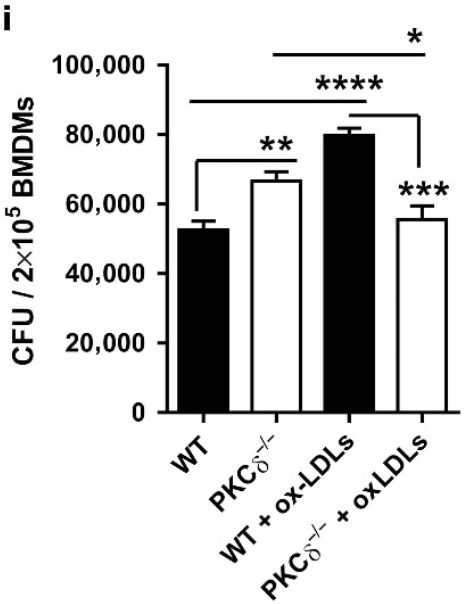

Figure 7 Decreased production of killing effector molecules with no effect on phagosome maturation and autophagy in protein kinase-C $\delta$-deficient $\left(\mathrm{PKC} \delta^{-l-}\right.$ ) macrophages. (a, b) Western blot and densitometry analysis of phagosome (LAMP-1, LAMP-3, and Cathepsin-D (Cath D)) and autophagy (LC3-II) markers in total macrophage cell lysates following Mycobacterium tuberculosis (Mtb) infection. (c, d) Impaired production of nitric oxide in PKC $\delta$ macrophages measured by Griess reagent assay and quantitative reverse transcription-PCR (qRT-PCR). (e, f) Deficiency of PKC $\delta$ resulted in decreased production of hydrogen peroxide $\left(\mathrm{H}_{2} \mathrm{O}_{2}\right)$ and reactive oxygen species (ROS). (g) Percentage of live, dead, and apoptotic macrophages (Mphs) after 3 days of infection determined by Annexin V and 7-aminoactinomycin (7-AAD) staining. (h) Supernatants from 3-day-infected wild-type (WT) and $\mathrm{PKC} \delta^{-1-}$ macrophages were exchanged on $4 \mathrm{~h}$-infected $\mathrm{PKC} \delta^{-1-}(\mathrm{WT} \mathrm{SN})$ and WT $\left(\mathrm{PKC} \delta^{-}-\mathrm{SN}\right.$ ) macrophages to determine bacterial growth at day 3 after infection. (i) Macrophages from wild-type and $\mathrm{PKC} \delta^{-1-}$ mice were pretreated with or without oxidized low-density lipoproteins (Ox-LDLs) overnight. Cells were then infected with Mtb-containing medium with or without Ox-LDLs for 3 days to determine mycobacterial growth. Data are represented as mean \pm s.e.m. of quadruplicate and are representative of three independent experiments. Data are analyzed using unpaired Student's $t$-test, ${ }^{\star} P<0.05,{ }^{\star \star} P<0.01,{ }^{* \star \star} P<0.001,{ }^{\star \star \star *} P<0.0001$, vs. WT control macrophages.

the pathogen in the lung. Consistently, we found $\mathrm{PKC} \delta$ as an indicator of lung inflammation in yet another whole-blood transcriptome data set from pulmonary infections such as sarcoidosis, TB, pneumonia, and lung cancer. ${ }^{32}$ Given the nonspecificity to $\mathrm{TB}$ and substantial overlap in $\mathrm{PKC} \delta$ expression between our cohorts, this kinase offers a limitation to be used as a prognostic marker. Distinctly using mass spectrometry, we showed that the expression of PKC $\delta$ varies within the regions of lung granuloma. Notably, anti-TB therapy decreased PKC $\delta$ expression in whole blood of human patients, reflecting a potential role for this protein kinase as a host factor regulating $M t b$-driven inflammation.

Our findings revealed that $\mathrm{PKC} \delta$ is indeed associated with host defense against murine TB as PKC $\delta$ ablation enhanced 
Table 2 Serum fatty acid concentrations $\left(\mu \mathrm{gl}^{-1}\right)$ for the wild type and PKC $\delta^{-I}$ mice at 8 weeks after infection

\begin{tabular}{|c|c|c|c|c|c|c|c|c|c|}
\hline \multirow[t]{2}{*}{ Compound name } & \multicolumn{2}{|c|}{ Wild type } & \multicolumn{2}{|c|}{$\mathrm{PKC}^{-1-}$} & \multirow{2}{*}{$\begin{array}{l}P \text { value } \\
<0.05\end{array}$} & \multirow{2}{*}{$\begin{array}{l}\text { Effect size } \\
>0.8\end{array}$} & \multirow{2}{*}{$\begin{array}{l}\text { PCA powers } \\
>0.5\end{array}$} & \multirow{2}{*}{$\begin{array}{l}\text { PLS-DA VIP } \\
>1.0\end{array}$} & \multirow{2}{*}{$\begin{array}{l}\text { Fold } \\
\text { change }\end{array}$} \\
\hline & Conc & s.d. & Conc & s.d. & & & & & \\
\hline Eicosanoic acid (arachidic acid) & 7.49 & 2.96 & 2.60 & 0.15 & 0.045 & 1.652 & 0.623 & 7.334 & 2.88 \\
\hline Heneicosanoic acid & 0.24 & 0.12 & 0.10 & 0.07 & - & 1.143 & - & 4.287 & 2.40 \\
\hline Undecenoic acid & 0.93 & 0.13 & 0.40 & 0.49 & - & 1.077 & 0.840 & 5.312 & 2.33 \\
\hline Hexadecanoic acid (palmitic acid) & 27.84 & 18.68 & 13.07 & 8.88 & - & - & - & 3.674 & 2.13 \\
\hline Pentadecanoic acid (pentadecylic acid) & 6.97 & 1.14 & 4.42 & 2.77 & - & 0.918 & 0.636 & 3.733 & 1.58 \\
\hline Tridecanoic acid (tridecylic acid) & 0.67 & 0.11 & 0.52 & 0.15 & - & 1.067 & - & - & 1.29 \\
\hline 15-Tetracosenoic acid (nervonic acid) & 1.16 & 0.44 & 0.38 & 0.44 & 0.046 & 1.767 & - & - & 3.05 \\
\hline 9-Octadecenoic acid (oleic acid) & 0.23 & 0.05 & 0.82 & 0.35 & 0.042 & 1.695 & - & 3.912 & 0.28 \\
\hline Palmitelaidic acid & 0.13 & 0.04 & 0.05 & 0.03 & 0.019 & 2.014 & 0.763 & 6.327 & 2.60 \\
\hline $\begin{array}{l}\text { 9,12,15-Octadecatrienoic acid } \\
(\alpha \text {-linolenic acid) }\end{array}$ & 1.96 & 0.53 & 0.39 & 0.49 & 0.005 & 2.961 & 0.768 & 13.193 & 5.03 \\
\hline $\begin{array}{l}\text { 4,7,10,13,16,19-Docosahexaenoic acid } \\
\text { (cervonic acid) }\end{array}$ & 0.14 & 0.10 & 0.05 & 0.11 & - & 0.814 & 0.570 & - & 2.80 \\
\hline $\begin{array}{l}\text { 8,11,14-Eicosatrienoic acid } \\
\text { (homo- } \gamma \text {-linolenic acid) }\end{array}$ & 2.59 & 0.49 & 2.11 & 0.43 & - & 0.993 & - & - & 1.23 \\
\hline $\begin{array}{l}\text { 9,12-Octadecadienoic acid } \\
\text { (linoleic acid) }\end{array}$ & 1.37 & 0.41 & 0.68 & 0.20 & 0.037 & 1.660 & 0.692 & 1.293 & 2.01 \\
\hline $\begin{array}{l}\text { 5,8,11,14,17-Eicosapentaenoic acid } \\
\text { (timnodonic acid) }\end{array}$ & 17.46 & 2.21 & 7.06 & 7.53 & - & 1.382 & 0.709 & 2.715 & 2.47 \\
\hline 5,8,11-Eicosatrienoic acid (mead acid) & 0.25 & 0.11 & 1.20 & 0.76 & - & 1.245 & 0.590 & 10.320 & 0.21 \\
\hline 9-Hexadecenoic acid (palmitolinoleic acid) & 38.79 & 5.85 & 23.81 & 8.47 & 0.031 & 1.769 & - & 1.387 & 1.63 \\
\hline
\end{tabular}

mortality with rapid weight loss, high bacterial loads, and exacerbated lung pathology. In these mice, we found higher levels of lung proinflammatory cytokines during $M t b$ infection, consistent with our published reports on the role of $\mathrm{PKC} \delta$ in listeriosis ${ }^{7}$ and cutaneous leishmaniasis. ${ }^{6}$ Remarkably, inhibition of PKC $\delta$ using a specific peptide inhibitor TatV $\delta 1.1$ (ref. 23) recapitulated aggravated lung inflammation in $\mathrm{PKC} \delta^{-1-}$ mice during $M t b$ infection, revealing a direct role of this kinase in regulation of lung inflammation.

Alveolar macrophages (AMs) are essential for protection during $M t b$ infection in mice, ${ }^{33}$ and we found strikingly reduced numbers of AMs with concomitantly higher lung bacterial loads that could lead to necrosis in $\mathrm{PKC} \delta^{-/-}$mice. To control enhanced bacterial burdens, activated macrophages and monocytes are recruited that perhaps explain excessive NO oxide in the $\mathrm{PKC} \delta^{-1-}$ lungs, in contrast to $\mathrm{PKC} \delta^{-1-}$ macrophages in vitro. Notably, mice deficient in AMs due to the deletion of granulocyte-macrophage colony-stimulating factor develop a disorder of accumulated surfactant lipids in the alveolar spaces of the lungs. ${ }^{34}$ Despite reduced AMs in PKC $\delta^{-1-}$ mice, we did not observe increased lipid staining in the lungs. This could be due to the increased recruitment of activated macrophages that catabolize surfactant lipids along with type II alveolar epithelial cells. ${ }^{35}$ Importantly, it is feasible 
that due to higher bacterial burden AMs decreased in $\mathrm{PKC} \delta^{-1-}$ mice. Consequently, increased inflammatory cell recruitment to the lungs as a result of proinflammatory cytokines, which in turn might have decreased alveolar spaces (for gas exchange), translated in the mortality in these mice during $M t b$ infection. Our findings suggest that PKC $\delta$ is required for maintenance of an optimal inflammatory balance during $M t b$ infection that is a key factor in limiting immunopathology to host lung tissue. We infer from these findings where $\mathrm{PKC} \delta$ ablation in mice renders them hypersusceptible to $\mathrm{TB}$, and therefore it is likely that increased expression (blood) and abundance (granulomas) of this kinase reflect its role as a host factor to contain ongoing inflammation in humans.

Host lipid bodies provide an excellent nutrient source for the survival of intracellular $M t b,{ }^{36}$ thereby decreasing its own metabolism ${ }^{37}$ that allows pathogenesis ${ }^{38}$ and persistence ${ }^{12,39,40}$ of the bacterium. The necessity of triacylglycerol for slow replication was demonstrated in a recent study where deposition of excessive triacylglycerol in $M t b$ bacterium slowed down its growth as opposed to a $M t b$ strain capable of pumping out lipids. ${ }^{41}$ Reports have indicated a critical role of PKC $\delta$ in the accumulation of cholesterol in human ${ }^{22}$ and mouse ${ }^{15}$ macrophages and triacylglycerol during glucose intolerance induced by high-fat diet in $\mathrm{PKC} \delta{ }^{-1-}$ mice. ${ }^{10}$ Corroborating with these findings, we found that $\mathrm{PKC} \delta$ is indeed critical for the accumulation of lipids in the lungs, macrophages, and to a lesser extent in the case of serum fatty acids following $M t b$ infection. The latter may not contribute much to the biological relevance owing to subtle differences. Notably, it has been shown that in steady state, absence of PKC $\delta$ is dispensable for the uptake of Ox-LDL to induce foam cell formation in murine and human macrophages. ${ }^{42}$

Moreover, our observations of $M t b$ loads in $\mathrm{PKC} \delta^{-1-}$ macrophages pretreated with unsaturated, saturated fatty acids, and oxidized and native LDLs supported that lipid accumulation might not necessarily contribute to the intracellular bacterial growth in macrophages deficient for PKC $\delta$. Recently, it was shown that increased lipids in lungs and macrophages drive the polarization of macrophages (M2) involved in fibrosis. ${ }^{43}$ In $\mathrm{PKC} \delta^{-1-}$ mice, the decreased availability of lipids and enhanced proinflammatory cytokines might have limited tissue repair processes in the lungs. Thus, lipid accumulation can be the consequence rather than the cause of susceptibility to $M t b$ infection in $\mathrm{PKC} \delta^{-1-}$ mice. This $M t b$-driven modulation of host lipids may be the means by which this highly evolved pathogen controls its replication rate in vivo. It is feasible that inability of $\mathrm{PKC} \delta^{-1-}$ mice to accumulate intracellular lipids hampers the ability of $M t b$ to undergo slow-replicative state during infection.

Intracellular $M t b$ can be eliminated by the induction of macrophage phagosome maturation ${ }^{44}$ and autophagy. ${ }^{45}$ The PKC isoforms, including $\beta^{27}$ and $\alpha,{ }^{28}$ were reported to be important for maturation of $M t b$-containing phagosomes. In contrast to $\mathrm{PKC} \beta$ and $\mathrm{PKC} \alpha$, our findings indicated that $\mathrm{PKC} \delta$ is dispensable for phagosome maturation and autophagy in $M t b$-infected macrophages. An alternative explanation is that
PKC $\delta$, unlike other isoforms $(\alpha, \beta$, and $\gamma)$, is insensitive to calcium signaling ${ }^{46}$ that is important for phagosome maturation. Another isoform $\mathrm{PKC} \zeta$ has been implicated as a key factor for TLR2-ERK1/2 (Toll-like receptor 2/extracellular signalregulated kinase 1/2)-mediated secretion of TNF in both murine and human macrophages following $M t b$ infection in vitro. ${ }^{47}$ However, inhibition of $\mathrm{PKC} \delta$ with rottlerin abrogated apoptosis in murine macrophages when cultured with cell-free supernatant of Mycobacterium indicus pranni $(M w){ }^{48}$ In contrast, we observed increased apoptosis in $\mathrm{PKC}^{-1-}$ macrophages following $M t b$ infection. This observation strengthens accumulating evidence regarding the nonspecific actions of rottlerin as a PKC $\delta$ inhibitor. ${ }^{13,42}$

As we found no effect on phagosome maturation and autophagy, we probed other effector functions in which PKC $\delta$ might be involved. It is well established that within macrophages, $M t b$ can be successfully eradicated by oxidative (ROS, $\mathrm{H}_{2} \mathrm{O}_{2}$ ) and nitrosative (NO) killing functions. ${ }^{29}$ Interestingly, IFN- $\gamma$-activated macrophages synergistically increase NO production by fivefold upon phorbol 12-myristate 13-acetate-mediated PKC activation in Mycobacterium bovis (Bacillus Calmette-Guérin (BCG))-infected macrophages. ${ }^{49}$ Indeed, this was confirmed in our study as the presence of PKC $\delta$ enhanced killing effector functions, whereas the absence thereof inhibited these effector responses, thereby reducing the mycobacterial killing capacity of $\mathrm{PKC} \delta^{-1-}$ macrophages. To our knowledge, there has been no report on a functional role for PKC $\delta$ in immunity to $\mathrm{TB}$ in mice and humans.

Collectively, our data revealed that PKC $\delta$ is an indicator of inflammation in both systemic and local tissue compartments during active TB disease progression in humans. Global deletion of PKC $\delta$ worsens the $M t b$ disease outcome in mice that exaggerated mortality with a shift toward increased bacterial burdens, exacerbated pathology, and excessive proinflammatory responses. To a lesser extent following $M t b$ infection, decreased lipids in lungs and macrophages of $\mathrm{PKC} \delta^{-1-}$ mice might further reduce the possibility for this bacterium to undergo persistence. Mechanistically, reduced killing effector functions in macrophages increased susceptibility to $M t b$ in the absence of PKC $\delta$. Taken together, the onset of active human $M t b$ disease correlates with PKC $\delta$ expression, and conferring from our murine model, PKC $\delta$ might be a critical factor employed by the host to control exacerbation of $M t b$ infection.

\section{METHODS}

Whole-blood mRNA signature of PKC. For whole-blood transcriptomics, we analyzed the publicly available RNA-sequencing data set from the Adolescent Cohort Study. ${ }^{19}$ We determined expression profiles of all PKC isoforms from 800 days before diagnosis of TB disease. A detailed description of the study and analysis is mentioned in Supplementary Methods.

A cross-sectional cohort of TB disease and healthy control participants. This was a cross-sectional study of 30 healthy HIV-negative adults with latent $M t b$ infection and 30 HIV-negative adults with active pulmonary TB disease recruited from the Western Cape region of South Africa. The human Study protocol (HEC: 288/ 
2008) was approved by the University of Cape Town, Human Ethics Committee. Participants were recruited following written informed consent before inclusion in the study. Latent $M t b$ infection was diagnosed by QuantiFERON TB Gold in-tube assay (Qiagen, Hilden, Germany, IFN- $\gamma$ levels $>0.35 \mathrm{IU} \mathrm{ml}^{-1}$ ) and TB disease was diagnosed as sputum-positive positive Xpert MTB/RIF test (Cepheid, Sunnyvale, CA). Whole blood in PAXgene blood RNA tubes (PreAnalytix, Hombrechtikon, Switzerland) was collected from each participant.

Human $\mathrm{PKC} \delta$ expression following treatment and lung proteomics from treatment-refractory TB patients. The blood gene signature from the publically available data set in the NCBI-GEO (National Center for Biotechnology Information Gene Expression Omnibus) database, accession number GSE31348, was used to analyze PKC expression of all isoforms during TB treatment. ${ }^{20}$ For human lung proteomics, we analyzed the available data that have been deposited into the PRIDE partner repository with the data set identifier PXD003646. The heat map plot was constructed by calculating $z$-scores of PKC $\delta$ abundance in different types of granulomas derived from multidrug-resistant TB patients. Details of the patients and surgical procedures have been described previously. ${ }^{21}$

Mice. PKC $\delta$-deficient $\left(\mathrm{PKC} \delta^{-/-}\right)$mice on the $129 \mathrm{~Sv}$ genetic background (8-12 weeks) were maintained under specific pathogenfree conditions in individually ventilated cages. All experiments were performed in accordance with the South African National Guidelines and University of Cape Town practice for laboratory animal procedures. The protocol (AEC: 012/036) was approved by the Animal Ethics Committee, Faculty of Health Sciences, University of Cape Town, Cape Town, South Africa.

Mtb infection and determination of bacterial loads in mice. Mtb $(\mathrm{H} 37 \mathrm{Rv})$ was grown to log phase in $7 \mathrm{H} 9$ complete media, and stocks were prepared for infections via an intranasal route as described previously. ${ }^{50}$ Bacterial loads in lungs and spleen of $M t b$-infected mice were determined at indicated time points after infection. Briefly, organs from killed mice were removed aseptically, weighed, and homogenized in $0.04 \%$ Tween- 80 . Tenfold dilutions were plated onto Middlebrook 7H10 (BD Biosciences, San Jose, CA) agar plates supplemented with $10 \%$ OADC and $0.5 \%$ glycerol and incubated at $37^{\circ} \mathrm{C}$ for 21 days before colonies were counted.

Histopathology, immunohistochemistry, and lipid staining of the lungs. Formalin-fixed (10\%) lung tissue from $M t b$-infected mice was cut into $3 \mu \mathrm{m}$ sections and stained with hematoxylin and eosin for histopathological analysis. For iNOS staining, immunohistochemistry was performed using rabbit anti-mouse iNOS (Abcam, Cambridge, UK) as described previously. ${ }^{51}$ Neutral lipids were analyzed in lung sections of $M t b$-infected mice or macrophages by Oil Red O (SigmaAldrich, St. Louis, MO) staining for $5 \mathrm{~min}$ following washing and then a rinse with $60 \%$ isopropanol. ${ }^{52}$ Sections were mounted using the gelatine-based mounting medium. Image acquisition and quantification of lesion area, iNOS staining, and area covered by lipid bodies were performed on a Nikon (Tokyo, Japan) 90i microscope using NIS advanced software.

Cytokine responses and immune cell populations in lungs using fluorescence-activated cell sorting. Supernatants from lung homogenates were collected for the determination of cytokines. IFN $-\gamma$, TNF, IL-6, IL-10 (all from BD Biosciences, San Jose, CA), IL-1 $\beta$ (R\&D Systems, Minneapolis, MN), and IFN- $\beta$ (Biolegend, San Diego, CA) productions were quantified in these supernatants by enzyme-linked immunosorbent assay. Single-cell suspension of $M t b$-infected lungs was prepared following collagenase digestion as previously described. ${ }^{51}$ Cells were then stained for lymphocytes $\left(\mathrm{CD} 4{ }^{+}, \mathrm{CD} 8^{+} \mathrm{T}\right.$ cells and $\mathrm{B}$ cells) and myeloid populations (alveolar macrophages, activated macrophages, dendritic cells, and neutrophils). Surface phenotyping of various cell populations was performed using the following antibodies: CD3-FITC, CD4-PE, CD8-APC, CD19-PerCP, CD11c-APC, CD11b-
PE, MHCII-FITC, Siglec-F-PE, and Gr-1-FITC (all from BD Biosciences). Cells were acquired on a FACS Calibur and the data were analyzed using FlowJo software (v10.1, Tree Star, Ashland, OR) as described previously. ${ }^{51}$

Metabolome analysis in serum of $\operatorname{PKC} \delta$ mice using gas chromatography-mass spectrometry. Extraction of the collected serum samples from $M t b$-infected $\mathrm{PKC} \delta^{-1-}$ and wild-type mice at 4 and 8 weeks after infection was performed as previously described ${ }^{53}$ using $50 \mu \mathrm{l}$ of $0.45 \mu \mathrm{g} \mathrm{ml}^{-1} 3$-phenylbutyric acid (Sigma-Aldrich) as an internal standard before gas chromatography by gas chromatography with time-of-flight mass spectrometry (GC $\times$ GC-TOFMS) analyses. A detailed description is included in Supplementary Methods.

Mtb infection in vitro. Murine BMDMs and human MDMs were generated as previously described. ${ }^{50}$ Macrophages were pretreated with either Ox-LDLs $\left(100 \mu \mathrm{g} \mathrm{ml}^{-1}\right)$, native-LDLs $\left(125 \mu \mathrm{g} \mathrm{ml}^{-1}\right)$, oleic acid $(500 \mu \mathrm{M})$, palmitic acid $(500 \mu \mathrm{M})$, or left untreated overnight. Cells were then infected in the presence of treatment(s) with $M t b(\mathrm{H} 37 \mathrm{Rv}$, unless otherwise indicated) with multiplicity of infection of 2. At indicated time points, cells were lysed in $0.1 \%$ Triton X-100 for determination of bacterial growth or fixed using $4 \%$ paraformaldehyde for visualization of bacteria and Oil Red $\mathrm{O}$ staining. Images were acquired using a Carl Zeiss 510 (Jena, Germany) confocal microscope and bright-field images were analyzed for the area under the lipid stain as mentioned above.

Quantitative RT-PCR from whole blood, human MDMs, and murine BMDMs. A total of 16 RNA samples from QuantiFERON (QFT, Qiagen, Hilden, Germany)-positive and -negative and $8 \mathrm{~TB}$ progressor subjects were validated for the expression of PKC $\delta$ using qRT-PCR from the Adolescent Cohort Study. RNA was extracted from whole blood (PAXgene blood RNA kit, Qiagen) followed by complementary DNA synthesis using Superscript II Reverse Transcriptase (Life Technologies, Waltham, MA). $M t b$-infected BMDMs or MDMs were reverse transcribed by Transcriptor First-Strand complementary DNA Synthesis Kit (Roche, Basel, Switzerland). Real-time PCR was performed with LightCycler 480 SYBR Green I Master mix using a LightCycler 480 II (Roche) for relative expression of $\mathrm{PKC} \delta$ relative to HPRT housekeeping gene.

Western blot analysis. Sodium dodecyl sulfate-polyacrylamide gel electrophoresis and western blot analysis was performed as previously described. ${ }^{50}$ Briefly, macrophages $\left(3 \times 10^{6}\right)$ were infected with $M t b$ at multiplicity of infection of 2 for $4 \mathrm{~h}$. Cells were washed and then lysed with ice-cold RIPA buffer containing protease inhibitors for $30 \mathrm{~min}$ at $4{ }^{\circ} \mathrm{C}$. Total cell lysates were analyzed for protein contents using BCA assay (ThermoFisher, Waltham, MA). An equal amount of protein $(40 \mu \mathrm{g})$ was then electrophoresed on $12 \%$ sodium dodecyl sulfatepolyacrylamide gel electrophoresis and transferred to a nitrocellulose membrane (Sigma). The membrane was probed with anti-LAMP-1, LAMP-3, Cathepsin-D, LC3-II, and GAPDH primary antibodies diluted (1:200) in blocking buffer at $4{ }^{\circ} \mathrm{C}$ overnight. The membrane was then incubated with the horseradish peroxidase-conjugated secondary antibody $(1: 10,000)$ for $1 \mathrm{~h}$ at room temperature in blocking buffer. Immunoblots were developed using Super Signal West Dura substrate (Pierce, Waltham, MA).

Measurements of $\mathrm{NO}, \mathrm{H}_{2} \mathrm{O}_{2}$, ROS, and Oil Red O staining in BMDMs. Cell supernatants from infected macrophages were collected for measurement of $\mathrm{NO}$ using Griess reagent. $\mathrm{H}_{2} \mathrm{O}_{2}$ release from macrophages was measured using colorimetric detection kit (Amplex Red Hydrogen Peroxide Assay, ThermoFisher). ROS was determined in macrophages using nitroblue tetrazolium (NBT, Sigma-Aldrich) that is reduced to a dark-blue insoluble formazan. Cells were incubated for phosphate-buffered saline containing $0.2 \%$ NBT for $90 \mathrm{~min}$. Formazan was dissolved in $0.04 \% \mathrm{HCL}$ in isopropanol, and the absorbance was 
determined at $560 \mathrm{~nm} .^{54}$ Quantification of Oil Red O staining in macrophages was determined following solubilizing of lipid droplets in isopropanol and the absorbance was determined at $490 \mathrm{~nm} .{ }^{55}$

Statistics. All data were analyzed using GraphPad Prism v 6.0 (GraphPad, La Jolla, CA) and Student's $t$-test (two-tailed with unequal variance) unless otherwise stated. A $P$ value of 0.05 was considered significant. Statistics regarding RNA-sequencing data analysis is included in Supplementary Methods.

SUPPLEMENTARY MATERIAL is linked to the online version of the paper at http://www.nature.com/mi

\section{ACKNOWLEDGMENTS}

We thank the University of Cape Town (UCT) Animal Unit staff, Rodney Lucas for technical assistance, Faried Abbas for maintenance of the BSL3 facility, Nazila Ghodsi, Munadia Ansari, and Fadwah Booley for genotyping of mice and maintenance of laboratory, respectively. We also thank Lizette Fick, Marilyn Tyler, and Zoe Lotz for their histology services. We thank Dirk M. Lang and Susan Cooper for Department of Science and Technology and National Research Foundation (DST-NRF) core confocal microscope service and facility. This work was supported by postdoctoral fellowship(s), Arturo Falaschi Post-doctoral fellowship (ICGEB), Claude Leon Foundation and Centre for Infectious Disease Research Initiative (CIDRI)-Wellcome Trust (084323) to S.P.P., South African Medical Research Council (SAMRC) Unit on Immunology of Infectious Diseases to F.B., NRF Competitive Programme for Unrated Researchers (CSUR) and DST/NRF postgraduate training program to R.G., National Research Funding (NRF) and South African Research Chair initiative (SARCHi) to F.B. at the UCT, South Africa, NRF and SAMRC funding to M.J.M. The human work was supported by grants from the Bill and Melinda Gates Foundation (BMGF) Global Health grants OPP1021972, the National Institutes of Health (RO1-AI087915; U19Al106761), and the Strategic Health Innovation Partnerships (SHIP) Unit of the South African Medical Research Council with funds received from the South African Department of Science and Technology and $\mathrm{NIH}$-funded Omics for TB Disease progression grant (NIH/NIAID U19 Al106761).

\section{AUTHOR CONTRIBUTIONS}

Conceptualization: S.P.P., M.O., R.G., and F.B.; methodology: S.P.P., M.O., M.J.M., D.T.L., R.H., D.B., M.V.R., D.E.Z. and F.D.; investigation: S.P.P., M.O., M.J.M., D.T.L., D.E.Z., S.K.M., A.P.N. and T.J.S.; writing-original draft: S.P.P; writing-review and editing: S.P.P., M.O., M.J.M., R.H., D.T.L., D.E.Z., A.P.N., T.J.S., R.G., and F.B.; funding acquisition: R.G. and F. B.; Resources, M.L., M.J.M., D.T.L., W.E.H., T.J S. and F.B.; supervision: F.B.

\section{DISCLOSURE}

The authors declared no conflict of interest.

Official journal of the Society for Mucosal Immunology

\section{REFERENCES}

1. Denning, M.F., Dlugosz, A.A., Threadgill, D.W., Magnuson, T. \& Yuspa, S.H. Activation of the epidermal growth factor receptor signal transduction pathway stimulates tyrosine phosphorylation of protein kinase $\mathrm{C}$ delta. J. Biol. Chem. 271, 5325-5331 (1996).

2. Brodie, C. \& Blumberg, P.M. Regulation of cell apoptosis by protein kinase c delta. Apoptosis 8, 19-27 (2003).

3. Jackson, D.N. \& Foster, D.A. The enigmatic protein kinase Cdelta: complex roles in cell proliferation and survival. FASEB J. 18, 627-636 (2004).

4. Page, K. et al. Regulation of airway smooth muscle cyclin D1 transcription by protein kinase C-delta. Am. J. Respir. Cell Mol. Biol. 27, 204-213 (2002).

5. De Servi, B., Hermani, A., Medunjanin, S. \& Mayer, D. Impact of PKCdelta on estrogen receptor localization and activity in breast cancer cells. Oncogene 24, 4946-4955 (2005).

6. Guler, R. et al. PKCdelta regulates IL-12p40/p70 production by macrophages and dendritic cells, driving a type 1 healer phenotype in cutaneous leishmaniasis. Eur. J. Immunol. 41, 706-715 (2011).
7. Schwegmann, A. et al. Protein kinase C delta is essential for optimal macrophage-mediated phagosomal containment of Listeria monocytogenes. Proc. Natl. Acad. Sci. USA 104, 16251-16256 (2007).

8. Mecklenbrauker, I., Saijo, K., Zheng, N.Y., Leitges, M. \& Tarakhovsky, A. Protein kinase Cdelta controls self-antigen-induced B-cell tolerance. Nature 416, 860-865 (2002).

9. Miyamoto, A. et al. Increased proliferation of B cells and auto-immunity in mice lacking protein kinase Cdelta. Nature 416, 865-869 (2002).

10. Frangioudakis, G. et al. Diverse roles for protein kinase $\mathrm{C}$ delta and protein kinase $\mathrm{C}$ epsilon in the generation of high-fat-diet-induced glucose intolerance in mice: regulation of lipogenesis by protein kinase $\mathrm{C}$ delta. Diabetologia 52, 2616-2620 (2009).

11. Garton, N.J. et al. Cytological and transcript analyses reveal fat and lazy persister-like bacilli in tuberculous sputum. PLoS Med. 5, e75 (2008).

12. Russell, D.G., Cardona, P.J., Kim, M.J., Allain, S. \& Altare, F. Foamy macrophages and the progression of the human tuberculosis granuloma. Nat. Immunol. 10, 943-948 (2009).

13. Tapia, J.A., Jensen, R.T. \& Garcia-Marin, L.J. Rottlerin inhibits stimulated enzymatic secretion and several intracellular signaling transduction pathways in pancreatic acinar cells by a non-PKC-delta-dependent mechanism. Biochim. Biophys. Acta 1763, 25-38 (2006).

14. Contreras, X., Mzoughi, O., Gaston, F., Peterlin, M.B. \& Bahraoui, E. Protein kinase $\mathrm{C}$-delta regulates HIV-1 replication at an early post-entry step in macrophages. Retrovirology 9, 37 (2012).

15. Wang, Y. \& Oram, J.F. Unsaturated fatty acids phosphorylate and destabilize ABCA1 through a protein kinase C delta pathway. J. Lipid Res. 48, 1062-1068 (2007).

16. Larsen, E.C. et al. Differential requirement for classic and novel PKC isoforms in respiratory burst and phagocytosis in RAW 264.7 cells. J. Immunol. 165, 2809-2817 (2000).

17. Comalada, M., Xaus, J., Valledor, A.F., Lopez-Lopez, C., Pennington, D.J. \& Celada, A. PKC epsilon is involved in JNK activation that mediates LPS-induced TNF-alpha, which induces apoptosis in macrophages. Am. J. Physiol. Cell Physiol. 285, C1235-C1245 (2003).

18. Strasser, D. et al. Syk kinase-coupled C-type lectin receptors engage protein kinase $\mathrm{C}$-sigma to elicit Card9 adaptor-mediated innate immunity. Immunity 36, 32-42 (2012).

19. Zak, D.E. et al. A blood RNA signature for tuberculosis disease risk: a prospective cohort study. Lancet 387, 2312-2322 (2016).

20. Cliff, J.M. et al. Distinct phases of blood gene expression pattern through tuberculosis treatment reflect modulation of the humoral immune response. J. Infect. Dis. 207, 18-29 (2013).

21. Marakalala, M.J. et al. Inflammatory signaling in human tuberculosis granulomas is spatially organized. Nat. Med. 22, 531-538 (2016).

22. Ma, H.T. et al. Protein kinase $\mathrm{C}$ beta and delta isoenzymes mediate cholesterol accumulation in PMA-activated macrophages. Biochem. Biophys. Res. Commun. 349, 214-220 (2006).

23. Pabla, N. et al. Inhibition of PKCdelta reduces cisplatin-induced nephrotoxicity without blocking chemotherapeutic efficacy in mouse models of cancer. J. Clin. Invest. 121, 2709-2722 (2011).

24. Ichi, I. et al. Identification of genes and pathways involved in the synthesis of Mead acid (20:3n-9), an indicator of essential fatty acid deficiency. Biochim. Biophys. Acta 1841, 204-213 (2014).

25. Anes, E., Kunnel, M.P., Bos, E., Moniz-Pereira, J., Habermann, A. \& Griffiths, G. Selected lipids activate phagosome actin assembly and maturation resulting in killing of pathogenic mycobacteria. Nat. Cell Biol. 5, 793-802 (2003).

26. FANTOM Consortium and the RIKEN PMI and CLST (DGT) et al. A promoter-level mammalian expression atlas. Nature 507, 462-470 (2014).

27. Daniel, D.S. et al. The reduced bactericidal function of complement C5-deficient murine macrophages is associated with defects in the synthesis and delivery of reactive oxygen radicals to mycobacterial phagosomes. J. Immunol. 177, 4688-4698 (2006).

28. Chaurasiya, S.K. \& Srivastava, K.K. Downregulation of protein kinase C-alpha enhances intracellular survival of Mycobacteria: role of PknG. BMC Microbiol. 9, 271 (2009).

29. Nathan, C. \& Shiloh, M.U. Reactive oxygen and nitrogen intermediates in the relationship between mammalian hosts and microbial pathogens. Proc. Natl. Acad. Sci. USA 97, 8841-8848 (2000). 
30. Tobin, D.M. et al. Host genotype-specific therapies can optimize the inflammatory response to mycobacterial infections. Cell 148, 434-446 (2012).

31. Kim, M.J. et al. Caseation of human tuberculosis granulomas correlates with elevated host lipid metabolism. EMBO Mol. Med. 2, 258-274 (2010).

32. Bloom, C.I. et al. Transcriptional blood signatures distinguish pulmonary tuberculosis, pulmonary sarcoidosis, pneumonias and lung cancers. PLoS ONE 8, e70630 (2013).

33. Gonzalez-Juarrero, M. et al. Disruption of granulocyte macrophage-colony stimulating factor production in the lungs severely affects the ability of mice to control Mycobacterium tuberculosis infection. J. Leukoc. Biol. 77, 914-922 (2005).

34. Dranoff, G. et al. Involvement of granulocyte-macrophage colony-stimulating factor in pulmonary homeostasis. Science 264, 713-716 (1994).

35. Malloy, J.L. \& Wright, J.R. In vivo clearance of surfactant lipids during acute pulmonary inflammation. Respir. Res. 5, 8 (2004).

36. Peyron, P. et al. Foamy macrophages from tuberculous patients' granulomas constitute a nutrient-rich reservoir for $M$. tuberculosis persistence. PLoS Pathog. 4, e1000204 (2008).

37. Caceres, N. et al. Evolution of foamy macrophages in the pulmonary granulomas of experimental tuberculosis models. Tuberculosis (Edinb) 89, 175-182 (2009).

38. Marrero, J., Rhee, K.Y., Schnappinger, D., Pethe, K. \& Ehrt, S. Gluconeogenic carbon flow of tricarboxylic acid cycle intermediates is critical for Mycobacterium tuberculosis to establish and maintain infection. Proc. Natl. Acad. Sci. USA 107, 9819-9824 (2010).

39. Daniel, J., Maamar, H., Deb, C., Sirakova, T.D. \& Kolattukudy, P.E. Mycobacterium tuberculosis uses host triacylglycerol to accumulate lipid droplets and acquires a dormancy-like phenotype in lipid-loaded macrophages. PLoS Pathog. 7, e1002093 (2011).

40. Pandey, A.K. \& Sassetti, C.M. Mycobacterial persistence requires the utilization of host cholesterol. Proc. Natl. Acad. Sci USA 105, 4376-4380 (2008).

41. Martinot, A.J. et al. Mycobacterial metabolic syndrome: LprG and Rv1410 regulate triacylglyceride levels, growth rate and virulence in Mycobacterium tuberculosis. PLoS Pathog. 12, e1005351 (2016).

42. Szilagyi, K. et al. PKCdelta is dispensible for oxLDL uptake and foam cell formation by human and murine macrophages. Cardiovasc. Res. 104, 467-476 (2014).

43. Romero, F. et al. A pneumocyte-macrophage paracrine lipid axis drives the lung toward fibrosis. Am. J. Respir. Cell Mol. Biol. 53, 74-86 (2015).

44. MacMicking, J.D., Taylor, G.A. \& McKinney, J.D. Immune control of tuberculosis by IFN-gamma-inducible LRG-47. Science 302, 654-659 (2003).

45. Gutierrez, M.G., Master, S.S., Singh, S.B., Taylor, G.A., Colombo, M.I. \& Deretic, V. Autophagy is a defense mechanism inhibiting BCG and
Mycobacterium tuberculosis survival in infected macrophages. Cell 119, 753-766 (2004).

46. Kazanietz, M.G. et al. Characterization of ligand and substrate specificity for the calcium-dependent and calcium-independent protein kinase C isozymes. Mol. Pharmacol. 44, 298-307 (1993).

47. Yang, C.S. et al. Protein kinase C zeta plays an essential role for Mycobacterium tuberculosis-induced extracellular signal-regulated kinase $1 / 2$ activation in monocytes/macrophages via Toll-like receptor 2 . Cell Microbiol. 9, 382-396 (2007).

48. Pandey, R.K., Bhatt, K.H., Dahiya, Y. \& Sodhi, A. Mycobacterium indicus pranii supernatant induces apoptotic cell death in mouse peritoneal macrophages in vitro. PLOS ONE 6, e17093 (2011).

49. Olivier, M. et al. Phenotypic difference between Bcg(r) and Bcg(s) macrophages is related to differences in protein-kinase-C-dependent signalling. Eur. J. Biochem. 251, 734-743 (1998).

50. Parihar, S.P. et al. Statin therapy reduces the mycobacterium tuberculosis burden in human macrophages and in mice by enhancing autophagy and phagosome maturation. J. Infect. Dis. 209, 754-763 (2014).

51. Guler, R. et al. IL-4Ralpha-dependent alternative activation of macrophages is not decisive for Mycobacterium tuberculosis pathology and bacterial burden in mice. PLOS ONE 10, e0121070 (2015).

52. Fowler, S.D. \& Greenspan, P. Application of Nile red, a fluorescent hydrophobic probe, for the detection of neutral lipid deposits in tissue sections: comparison with oil red O. J. Histochem. Cytochem. 33, 833-836 (1985).

53. Williams, R. et al. A multi-analytical platform approach to the metabonomic analysis of plasma from normal and Zucker (fa/fa) obese rats. Mol. Biosyst. 2, 174-183 (2006).

54. Furukawa, S. et al. Increased oxidative stress in obesity and its impact on metabolic syndrome. J. Clin. Invest. 114, 1752-1761 (2004).

55. Lee, Y.J. et al. Antioxidant activity and anti-adipogenic effects of wild herbs mainly cultivated in Korea. Molecules 18, 12937-12950 (2013).

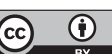

This work is licensed under a Creative Commons Attribution 4.0 International License. The images or other third party material in this articleareincluded in thearticle's Creative Commons license, unless indicated otherwise in the credit line; if the material is not included under the Creative Commons license, users will need to obtain permission from the license holder to reproduce the material. To view a copy of this license, visit http://creativecommons.org/licenses/by/4.0/

(C) The Author(s) 2018 